Check for updates

Cite this: RSC Adv., 2018, 8, 24209

Received 7th May 2018

Accepted 15th June 2018

DOI: $10.1039 / c 8 r a 03901 a$

rsc.li/rsc-advances

\section{Factorial design analysis of parameters for the sorption-enhanced steam reforming of ethanol in a circulating fluidized bed riser using CFD $\uparrow$}

\author{
Kiattikhoon Phuakpunk, ${ }^{a}$ Benjapon Chalermsinsuwan, (D) *bcd \\ Sompong Putivisutisak ${ }^{\text {de }}$ and Suttichai Assabumrungrat (iD) ad
}

\begin{abstract}
The sorption-enhanced steam reforming of ethanol (SESRE) has recently been reported as a novel process for hydrogen $\left(\mathrm{H}_{2}\right)$ production. SESRE can operate well on a Ni-based catalyst with dolomite as a sorbent in packed-bed reactors. In this study, the circulating fluidized bed (CFB) concept was proposed to obtain higher productivity and continuous operation of SESRE. Particular focus was directed to the design and selection of suitable operating conditions of the CFB riser. Two-dimensional transient models using the Euler-Euler approach and the kinetic theory of granular flows were applied to investigate the $\mathrm{H}_{2}$ production performance from a pilot-scale riser. The $2^{k}$ full factorial design method was utilized to examine the significances of five specific parameters, namely, the riser diameter, inlet temperature, catalyst-to-sorbent ratio, solid flux, and inlet gas velocity on two response variables, namely, $\mathrm{H}_{2}$ purity and $\mathrm{H}_{2}$ flux. From the ANOVA results, either the main effect or the interactions of each parameter were shown to be significant on both the $\mathrm{H}_{2}$ purity and the $\mathrm{H}_{2}$ flux, particularly the riser diameter and the solid flux. For optimizing the operation and reaction parameters, the best case was the system with riser diameter of 0.2 $\mathrm{m}$, inlet temperature of $600{ }^{\circ} \mathrm{C}$, catalyst-to-sorbent ratio of $2.54 \mathrm{~kg} \mathrm{~kg}^{-1}$, solid flux of $200 \mathrm{~kg} \mathrm{~m}^{-2} \mathrm{~s}^{-1}$, and gas velocity of $3 \mathrm{~m} \mathrm{~s}^{-1}$, obtaining $\mathrm{H}_{2}$ purity of $91.30 \%$ on a dry basis with a significantly high $\mathrm{H}_{2}$ flux of $0.147 \mathrm{~kg} \mathrm{~m}^{-2} \mathrm{~s}^{-1}$. The hydrodynamics showed that SESRE reached breakthrough within the bottom dense zone. However, incomplete conversion occurred in the core of the riser because of the very dilute bed.
\end{abstract}

\section{Introduction}

Nowadays, global fossil-fuel reservoirs are drastically depleting, while the world's energy-consumption tendency is constantly increasing. Hydrogen fuel is a promising alternative source and has drawn widespread attention because it is a clean energy source and can be derived from renewable energy sources. At the end use, when hydrogen $\left(\mathrm{H}_{2}\right)$ is combusted in internal engines or fed into fuel cells, only water is the end product without the emission of carbon dioxide $\left(\mathrm{CO}_{2}\right)$, a major cause of

${ }^{a}$ Center of Excellence in Catalysis and Catalytic Reaction Engineering, Department of Chemical Engineering, Faculty of Engineering, Chulalongkorn University, Bangkok, Thailand, 10330

${ }^{b}$ Fuels Research Center, Department of Chemical Technology, Faculty of Science, Chulalongkorn University, Bangkok, Thailand, 10330.E-mail: Benjapon.C@chula. ac.th

${ }^{c}$ Center of Excellence on Petrochemical and Materials Technology, Chulalongkorn University, Bangkok, Thailand, 10330

${ }^{d}$ Advanced Computational Fluid Dynamics Research Unit, Chulalongkorn University, Bangkok, Thailand, 10330

${ }^{e}$ Department of Mechanical Engineering, Faculty of Engineering, Chulalongkorn University, Bangkok, Thailand, 10330

$\dagger$ Electronic supplementary information (ESI) available. See DOI: 10.1039/c8ra03901a global warming. ${ }^{1}$ However, hydrogen cannot yet be claimed to be totally renewable or green because its large-scale sources and production currently come from petroleum industries.

Hydrogen is the third most abundant element on Earth. Most natural hydrogen does not exist in the form of $\mathrm{H}_{2}$ gas, but is found in organic compounds. There are many organic compounds that can be converted into $\mathrm{H}_{2}$ via many processes, e.g., dehydrogenation, gasification, and steam reforming. Steam reforming is the most effective process to produce $\mathrm{H}_{2}$ on a large scale. Conventional industrial-level hydrogen production typically uses methane $\left(\mathrm{CH}_{4}\right)$, in natural gas or in tail gas from the refinery process, as a raw material via the steam methane reforming (SMR) process.

Ethanol (EtOH) is another excellent feedstock for hydrogen production via the steam reforming process. Ethanol is a renewable organic compound that can be derived from the fermentation of biomasses. Thus, ethanol can potentially replace methane from petroleum industries for $\mathrm{H}_{2}$ production. The pathways for the steam reforming of ethanol (SRE) are dependent on the types of catalyst (e.g., Ni-, Pt-, Pd-, or Co-based catalysts) and their operation conditions. ${ }^{2-8}$ Through the pathway of ethanol reforming using the Ni-based catalyst, EtOH is first converted to acetaldehyde $\left(\mathrm{CH}_{3} \mathrm{CHO}\right)$ through an ethanol dehydrogenation (ETD) reaction, as expressed in reaction (1). 
Then, $\mathrm{CH}_{3} \mathrm{CHO}$ is converted to $\mathrm{CH}_{4}$ through an acetaldehyde decomposition (ACD) reaction, as expressed in reaction (2). ${ }^{\mathbf{9 - 1 3}}$

$$
\begin{gathered}
\mathrm{C}_{2} \mathrm{H}_{5} \mathrm{OH} \rightleftharpoons \mathrm{CH}_{3} \mathrm{CHO}+\mathrm{H}_{2} \quad \Delta H_{298}^{\circ}=+68.4 \mathrm{~kJ} \mathrm{~mol}^{-1} \\
\mathrm{CH}_{3} \mathrm{CHO} \rightleftharpoons \mathrm{CH}_{4}+\mathrm{CO} \quad \Delta H_{298}^{\circ}=-18.8 \mathrm{~kJ} \mathrm{~mol}^{-1}
\end{gathered}
$$

In practice, $\mathrm{CH}_{3} \mathrm{CHO}$ is an unstable intermediate and almost totally converted to $\mathrm{CH}_{4}$. Thus, ethanol reforming with excess steam obtains an EtOH conversion of about $100 \% .^{\mathbf{8 , 1 2 - 1 4}}$ In addition, the ETD and ACD reactions can be combined in the ethanol decomposition (EDC) reaction, in which EtOH is directly converted to $\mathrm{CH}_{4}$, $\mathrm{CO}$, and $\mathrm{H}_{2}$, as shown in reaction (3). ${ }^{15,16}$

$$
\mathrm{C}_{2} \mathrm{H}_{5} \mathrm{OH} \rightarrow \mathrm{CH}_{4}+\mathrm{CO}+\mathrm{H}_{2} \quad \Delta H_{298}^{\circ}=+49.6 \mathrm{~kJ} \mathrm{~mol}^{-1}
$$

Furthermore, steam can react directly with EtOH in another pathway to obtain $\mathrm{CH}_{4}$, similar to the EDC reaction. This reaction is called ethanol decomposition with steam (EDC/S), as expressed in reaction (4). ${ }^{17}$

$\mathrm{C}_{2} \mathrm{H}_{5} \mathrm{OH}+\mathrm{H}_{2} \mathrm{O} \rightarrow \mathrm{CH}_{4}+\mathrm{CO}_{2}+2 \mathrm{H}_{2} \quad \Delta H_{298}^{\circ}=+8.4 \mathrm{~kJ} \mathrm{~mol}^{-1}$

After ethanol is nearly completely converted to methane, methane could be further reformed with steam, similar to the conventional SMR process, via three reversible reactions: two involving steam methane reforming reactions (eqn (5) and (6)) and a water-gas shift (WGS) reaction (eqn (7)).

$$
\begin{gathered}
\mathrm{CH}_{4}+\mathrm{H}_{2} \mathrm{O} \rightleftharpoons \mathrm{CO}+3 \mathrm{H}_{2} \quad \Delta H_{298}^{\circ}=+206.2 \mathrm{~kJ} \mathrm{~mol}^{-1} \\
\mathrm{CH}_{4}+2 \mathrm{H}_{2} \mathrm{O} \rightleftharpoons \mathrm{CO}_{2}+4 \mathrm{H}_{2} \quad \Delta H_{298}^{\circ}=+165.0 \mathrm{~kJ} \mathrm{~mol}^{-1} \\
\mathrm{CO}+\mathrm{H}_{2} \mathrm{O} \rightleftharpoons \mathrm{CO}_{2}+\mathrm{H}_{2} \quad \Delta H_{298}^{\circ}=-41.2 \mathrm{~kJ} \mathrm{~mol}^{-1}
\end{gathered}
$$

Overall, EtOH is converted to mainly $\mathrm{CO}_{2}$ and $\mathrm{H}_{2}$ (with minor amounts of $\mathrm{CO}$ and unreacted $\mathrm{CH}_{4}$ ) in the pathway involving the Ni-based catalyst. Notably, the main reactions of SRE can be summarized as the "overall reaction of SRE," as shown in reaction (8).

$$
\mathrm{C}_{2} \mathrm{H}_{5} \mathrm{OH}+3 \mathrm{H}_{2} \mathrm{O} \rightleftharpoons 2 \mathrm{CO}_{2}+6 \mathrm{H}_{2} \quad \Delta H_{298}^{\circ}=+173.4 \mathrm{~kJ} \mathrm{~mol}^{-1}
$$

The overall reforming reactions of both ethanol and methane are strongly endothermic. Hence, the reactor system must be operated at high temperature. By considering thermodynamic equilibrium at $750{ }^{\circ} \mathrm{C}, 1 \mathrm{~atm}$, and a steam/ethanol molar ratio $(\mathrm{S} / \mathrm{E})$ of 6 , the maximum $\mathrm{H}_{2}$ production can approximately be only $70 \% \mathrm{H}_{2}$ on a dry basis at $100 \%$ conversion of $\mathrm{EtOH}$. The other produced gases consist of $19 \% \mathrm{CO}_{2}, 8 \%$ $\mathrm{CO}$, and $3 \% \mathrm{CH}_{4} \cdot{ }^{18}$ To further purify $\mathrm{H}_{2}$, the effluent gas must pass through additional separation units, such as a pressure swing adsorption (PSA) unit or amine scrubbing unit. ${ }^{19,20}$
On integrating sorbents in the reformers, the produced $\mathrm{CO}_{2}$ from reforming can be adsorbed, shifting forward the equilibrium of the reforming reactions, as shown in reactions (5)-(7). The first advantage of this sorption enhancement is an increase in conversion of $\mathrm{CH}_{4}$ (completely converting both EtOH and $\mathrm{CH}_{4}$ ) and the production of more $\mathrm{H}_{2}$. Second, capturing $\mathrm{CO}_{2}$ from the effluent gas can afford high purity $\mathrm{H}_{2}$, reaching $99 \%$ on a dry basis. ${ }^{\mathbf{1 4 , 1 9 , 2 1 - 2 3}}$ Thus, the separation units are unnecessary in SESRE processes. Other advantages are the use of lower operation temperature and lower energy consumption for exothermic adsorption and shifting of the reforming reactions. The reforming of EtOH with $\mathrm{CO}_{2}$ sorption is called the sorptionenhanced steam reforming of ethanol (SESRE). However, a limitation of SESRE is the discontinuous performance when the sorbent is almost full of captured $\mathrm{CO}_{2}$. The sorbent then has to release $\mathrm{CO}_{2}$ before it can be used in reprocessing in SESRE.

Several types of sorbent have been used and developed for $\mathrm{CO}_{2}$ capture, e.g., natural or pure metal oxides (e.g., $\mathrm{CaO}$ ), synthesis metal oxides (e.g., $\mathrm{Ca}_{x} \mathrm{Al}_{y} \mathrm{O}_{z}$ and $\mathrm{CaO}$ nanoparticles), alkali mixed metal oxides (e.g., $\mathrm{Li}_{4} \mathrm{SiO}_{4}$ ), hydrotalcite-like materials (HTCls), and modified sorbents (e.g., Ni-CaO- $\mathrm{Al}_{2} \mathrm{O}_{3}$ multifunctional catalyst/sorbent). The $\mathrm{CO}_{2}$ capacity, rate of $\mathrm{CO}_{2}$ caption, and stability of these sorbents are important properties to increase the performance of SESRE., ${ }^{3,9,11,13,19,24-27}$ The advantages of natural $\mathrm{CaO}$ sorbents, such as dolomite and limestone, are that they are inexpensive, easy to find, and have higher $\mathrm{CO}_{2}$ capacity than other sorbents. However, $\mathrm{CaO}$ sorbents have lower thermal cyclic stability than the other sorbents. The reversible reaction involving $\mathrm{CO}_{2}$ capture by $\mathrm{CaO}$ (carbonation) and the reverse reaction (decarbonation) is shown in reaction (9).

$$
\mathrm{CaO}+\mathrm{CO}_{2} \rightleftharpoons \mathrm{CaCO}_{3} \quad \Delta H_{298}^{\circ}=-178 \mathrm{~kJ} \mathrm{~mol}^{-1}
$$

Limestone consists mostly of $\mathrm{CaO}$, while dolomite contains mainly $\mathrm{CaO}$ and $\mathrm{MgO}$. $\mathrm{MgO}$ reduces the sintering of $\mathrm{CaO}$ and endows dolomite higher stability for $\mathrm{CO}_{2}$ capture, although decreasing the amount of $\mathrm{CaO}$ reduces the $\mathrm{CO}_{2}$ capacity of dolomite more than that of limestone. ${ }^{18,28}$ Thus, dolomite is chosen for the SESRE processes, which require a regeneration step to remove captured $\mathrm{CO}_{2}$. Even though SESRE requires energy for sorbent regeneration, it has higher thermal efficiency (ratio of hydrogen energy to the summation of energy input plus ethanol energy) (about 0.45-0.82) than that of SRE (about 0.33$0.61) .{ }^{11,29} \mathrm{Wu}$ et al. ${ }^{10}$ reported the energy consumption per $\mathrm{H}_{2}$ mole of SESRE of about $169 \mathrm{~kJ} \mathrm{~mol}_{\mathrm{H}_{2}}{ }^{-1}$ and thermal efficiency equal to 0.57 in a process without energy recovery operated at $500{ }^{\circ} \mathrm{C}$ and at an $\mathrm{S} / \mathrm{E}$ of 8.

In SESMR/SESRE experiments, bubbling bed reactors as well as the fixed bed reactors could produce high purity $\mathrm{H}_{2} \cdot{ }^{30-35}$ However, the bubbling bed reactor had lower pressure drop and better reaction distribution throughout the bed than the fixed bed. However, SESRE operating in the bubbling bed reactor still needs to stop the process to perform a regeneration step when the SESRE reaches breakthrough by reaching the $\mathrm{CO}_{2}$ capture limit in the sorbent. 
Recently, a circulating fluidized bed reactor (CFBR) was developed and expected to be useful as a reactor for large-scale hydrogen production because of its capability to be used with higher gas velocity and to simultaneously enable regeneration inside the reactor. ${ }^{36}$ Furthermore, CFBR could provide higher $\mathrm{H}_{2}$ productivity and lower pressure drop than the bubbling bed reactor. ${ }^{37}$ A general CFBR system consists of four main parts ${ }^{38}$ as follows:

(1) Riser: gas and solids come enter at the riser bottom. Solid particles are blown upward and removed off with the gas at the riser top.

(2) Cyclone: solid particles are separated from the gas and fall out at the cyclone bottom.

(3) Downer: solid particles from the cyclone fall and move out at the downer bottom. This unit could act as another reactor.

(4) Solid return system: solid particles return to the riser bottom.

Because SESRE is a very fast reaction, an increase in the feed (i.e., operating with a higher velocity of gas) can enable greater $\mathrm{H}_{2}$ production. The reformer is able to operate in the riser section, whereas the regenerator needs sufficient residence time to complete decarbornation and remove the undesired $\mathrm{CO}_{2}$. Thus, the downer section should act as a bubbling bed reactor for sorbent regeneration. The performance of $\mathrm{H}_{2}$ production in this CFBR system depends on the operation in the riser that performs the SESRE. However, the riser consists of a dilute zone and dense zone, which might lead to an incomplete SESRE. The CFBR efficiency for SESRE still has not been unveiled; thus, the riser design for SESRE will be further studied. ${ }^{39-41}$

As the CFBR system must be experimented at least on a pilot scale with appropriate design and operation, each trial of the experiments can waste expensive resources, particularly expensive materials such as the Ni-based catalyst. Consequently, computational fluid dynamics (CFD) have been utilized for the initial design of an optimal system before testing in real operations. The CFD simulations with appropriate models can give high accuracy and detailed results and can reduce the time and resources needed for the experiments. The hydrodynamics model combined with the kinetic models of SESRE can be simulated either in a 2D or 3D system. Even though the results from a 3D model are more accurate than those from a $2 \mathrm{D}$ model, the 3D model has much more computational demand and takes more time than the 2D model, particularly for transient simulations. In addition, in many cases, particularly with a cylindrical geometry, such as the riser, the $2 \mathrm{D}$ model provides results with sufficient accuracy. ${ }^{\mathbf{9 1 0 , 4 2 - 4 5}}$

The main purpose of this study was to investigate the feasibility of SESRE for hydrogen production in a pilot-scale CFBR system using computations to reduce the costs from further experiments. In this study, the $2 \mathrm{D}$ geometry of the riser was utilized to design a suitable pilot-scale riser for hydrogen production via SESRE by studying the expected design and reaction parameters, including the riser diameter $\left(i_{\mathrm{d}}\right)$, inlet temperature $\left(T_{\mathrm{in}}\right)$, catalyst-to-sorbent ratio (Cat/Sb), solid flux $\left(G_{\mathrm{s}}\right)$, and gas velocity $(U)$. All the simulations were solved by a commercial CFD program, ANSYS ${ }^{\circledR}$ Fluent ${ }^{\circledR}$ 15.0.7. The $\mathrm{H}_{2}$ flux and $\mathrm{H}_{2}$ purity of the effluent gas from the simulations were used as response variables in a $2^{k}$ full factorial design analysis. The optimum case would then be predicted and chosen to analyze the hydrodynamics in that system.

\section{Methodology}

\subsection{Computational fluid dynamics}

Computational fluid dynamics (CFD) is a modern branch of hydrodynamics using algorithms and numerical methods, such as discretization methods, to solve complex fluid problems. CFD is an art of considering models of conservation combined with correlation equations (constitutive equations) and other models, such as chemical kinetic models.

Fluidization is a gas-solid contacting phenomenon. There are two main approaches for fluid-particle multiphase flow modeling: the Euler-Euler approach and the Euler-Lagrange approach. ${ }^{\mathbf{4 6 , 4 7}}$ The Euler-Euler model is also called the granular flow model (GFM) in a gas-solid flow. The Eulerian framework is considered for all phases and treats solid particles like a fluid. The kinetic theory of granular flow (KTGF) that represents kinetic energy oscillation must be applied for any solid particle phase. ${ }^{48}$ This Euler-Euler model with KTGF is suitable and widely used for fluidization systems that have a large amount of solid particles. ${ }^{30,31,38,40,42,43,49-55}$

There are many research studies that used the Euler-Euler approach with KTGF for the simulations of fluidization either without a reaction (cold flow) $)^{50,56-58}$ or with a reaction (hot flow). ${ }^{30,31,40,42,43,49,51-54,59-61}$ The cold flow validations were presented in some studies to prove the suitability of the models using the Euler-Euler approach with KTGF and were used as a base case for further hot flow simulations. All of the cold flow validations showed good agreement with the experiments. ${ }^{56-58}$

The SMR kinetics developed by $\mathrm{Xu}$ and Froment ${ }^{62}$ and the carbonation kinetics developed by Sun et al. ${ }^{64}$ were validated in hot flow fluidization with good results. ${ }^{57}$ Then, these were continuously applied in almost all publications from the NTNU research group. ${ }^{30,31,40,42,49,51-54,59}$ In addition, this SMR kinetics approach was also validated in other studies with very good results. Such as showing that the percentage of $\mathrm{H}_{2}$ in effluent gas had a deviation of less than $0.5 \%$, as reported by Johnsen et $a{ }^{33}$ and a deviation of about $3.5 \%$ for SMR and $1 \%$ for SESMR, as reported by Chen et al. ${ }^{61}$ This might prove that both kinetic models were suitable for the future studies of fluidization with SESMR using a Ni-based catalyst and dolomite. Several kinetic models of SRE on a Ni-based catalyst were applied by some researchers, ${ }^{\text {9-12,15,17 }}$ but unfortunately there was no application with fluidization. The only kinetics approach for SRE applied on a typical Ni-based catalyst, such as $\mathrm{Ni}-\mathrm{Al}_{2} \mathrm{O}_{3},{ }^{15,17}$ is described next. The concerning conservation equations and the constitutive equations of the Euler-Euler model with KTGF chosen in this study are summarized in Tables S1 and S2, $\dagger$ respectively.

2.1.1 Kinetics of SRE. Two kinetic models of SRE on a typical Ni-based catalyst $\left(\mathrm{Ni}-\mathrm{Al}_{2} \mathrm{O}_{3}\right)$ were chosen in this study. The first SRE kinetics was the one applied in a study by De- 
Souza et al. ${ }^{15}$ while the other was that modeled from a kinetic study by Mas et al. $^{17}$

Model A. De-Souza et al. ${ }^{15}$ studied simulations of SRE using the favorable kinetic models of the SMR reactions (reactions (11)-(13)) together with the kinetic model of the EDC reaction (reaction (10)). Thus, this SRE approach included four reactions as follows.

$$
\begin{gathered}
\text { EDC: } \mathrm{C}_{2} \mathrm{H}_{5} \mathrm{OH} \rightarrow \mathrm{CH}_{4}+\mathrm{CO}+\mathrm{H}_{2} \\
\text { bSMR: } \mathrm{CH}_{4}+\mathrm{H}_{2} \mathrm{O} \rightleftharpoons \mathrm{CO}+3 \mathrm{H}_{2} \\
\text { gSMR: } \mathrm{CH}_{4}+2 \mathrm{H}_{2} \mathrm{O} \rightleftharpoons \mathrm{CO}_{2}+4 \mathrm{H}_{2} \\
\text { WGS: } \mathrm{CO}+\mathrm{H}_{2} \mathrm{O} \rightleftharpoons \mathrm{CO}_{2}+\mathrm{H}_{2}
\end{gathered}
$$

The power law kinetic rate of EDC is an irreversible first order rate derived by Sun et al. ${ }^{\mathbf{1 6}}$ as follows.

$$
r_{\mathrm{EDC}}=k_{\mathrm{EDC}} p_{\mathrm{EtOH}}
$$

where the rate constant of EDC is defined as follows.

$$
k_{\mathrm{EDC}}=\frac{4.55 \times 10^{-5}}{T} \exp \left[\frac{-2030}{T}\right],\left[\mathrm{kmol} \mathrm{Pa}^{-1} \mathrm{~kg}_{\mathrm{cat}}{ }^{-1} \mathrm{~s}^{-1}\right]
$$

The kinetic models of the SMR reactions widely applied in many research studies were developed by $\mathrm{Xu}$ and Froment. ${ }^{62}$ These reaction rates are reversible and non-linear as follows:

$$
\begin{aligned}
& r_{\mathrm{bSMR}}=\frac{k_{\mathrm{bSMR}}}{p_{\mathrm{H}_{2}}{ }^{2.5}}\left(p_{\mathrm{CH}_{4}} p_{\mathrm{H}_{2} \mathrm{O}}-\frac{p_{\mathrm{H}_{2}}{ }^{3} p_{\mathrm{CO}}}{K_{\mathrm{bSMR}}}\right) \frac{1}{\mathrm{DEN}^{2}} \\
& r_{\mathrm{gSMR}}=\frac{k_{\mathrm{gSMR}}}{p_{\mathrm{H}_{2}}{ }^{3.5}}\left(p_{\mathrm{CH}_{4}} p_{\mathrm{H}_{2} \mathrm{O}}{ }^{2}-\frac{p_{\mathrm{H}_{2}}{ }^{4} p_{\mathrm{CO}_{2}}}{K_{\mathrm{gSMR}}}\right) \frac{1}{\mathrm{DEN}^{2}} \\
& r_{\mathrm{WGS}}=\frac{k_{\mathrm{WGS}}}{p_{\mathrm{H}_{2}}}\left(p_{\mathrm{CO}} p_{\mathrm{H}_{2} \mathrm{O}}-\frac{p_{\mathrm{H}_{2}} p_{\mathrm{CO}_{2}}}{K_{\mathrm{WGS}}}\right) \frac{1}{\mathrm{DEN}^{2}} \\
& \mathrm{DEN}=1+K_{\mathrm{CO}} p_{\mathrm{CO}}+K_{\mathrm{H}_{2}} p_{\mathrm{H}_{2}}+K_{\mathrm{CH}_{4}} p_{\mathrm{CH}_{4}}+\frac{K_{\mathrm{H}_{2} \mathrm{O}} p_{\mathrm{H}_{2} \mathrm{O}}}{p_{\mathrm{H}_{2}}}
\end{aligned}
$$

where the rate constants of reaction i are defined as follows:

$$
\begin{aligned}
& k_{\mathrm{bSMR}}=9.708 \times 10^{-4} \exp \left[\frac{-240100}{R}\left(\frac{1}{T}-\frac{1}{648}\right)\right], \\
& {\left[\mathrm{kmol} \mathrm{Pa}^{0.5} \mathrm{~kg}_{\text {cat }}{ }^{-1} \mathrm{~s}^{-1}\right]} \\
& k_{\mathrm{gSMR}}=1.156 \times 10^{-4} \exp \left[\frac{-243900}{R}\left(\frac{1}{T}-\frac{1}{648}\right)\right] \text {, } \\
& {\left[\mathrm{kmol} \mathrm{Pa}^{0.5} \mathrm{~kg}_{\text {cat }}{ }^{-1} \mathrm{~s}^{-1}\right]} \\
& k_{\mathrm{WGS}}=1.2597 \times 10^{-6} \exp \left[\frac{-67130}{R}\left(\frac{1}{T}-\frac{1}{648}\right)\right] \text {, } \\
& {\left[\begin{array}{lll}
\mathrm{kmol} & \mathrm{kg}_{\mathrm{cat}}{ }^{-1} \mathrm{~Pa}^{-1} \mathrm{~s}^{-1}
\end{array}\right]}
\end{aligned}
$$

Also, the adsorption equilibrium constants of species $\mathrm{k}$ are expressed as follows.

$$
\begin{array}{r}
K_{\mathrm{CH}_{4}}=1.791 \times 10^{-6} \exp \left[\frac{38280}{R}\left(\frac{1}{T}-\frac{1}{823}\right)\right],\left[\mathrm{Pa}^{-1}\right] \\
K_{\mathrm{H}_{2} \mathrm{O}}=0.4152 \exp \left[\frac{-88680}{R}\left(\frac{1}{T}-\frac{1}{823}\right)\right],[-] \\
K_{\mathrm{CO}}=4.091 \times 10^{-4} \exp \left[\frac{70650}{R}\left(\frac{1}{T}-\frac{1}{648}\right)\right],\left[\mathrm{Pa}^{-1}\right] \\
K_{\mathrm{H}_{2}}=2.960 \times 10^{-7} \exp \left[\frac{82900}{R}\left(\frac{1}{T}-\frac{1}{648}\right)\right],\left[\mathrm{Pa}^{-1}\right]
\end{array}
$$

herein, the equilibrium constants of reaction i can be expressed according to the equations developed by Xiu et al. ${ }^{63}$

$K_{\mathrm{bSMR}}=$

$$
\begin{gathered}
\frac{101325^{2}}{\exp \left(0.2513 Z^{4}-0.3665 Z^{3}-0.58101 Z^{2}+27.1337 Z-3.277\right)} \\
{\left[\mathrm{Pa}^{2}\right]} \\
K_{\mathrm{gSMR}}=K_{\mathrm{bSMR}} K_{\mathrm{WGS}},\left[\mathrm{Pa}^{2}\right] \\
K_{\mathrm{WGS}}=\exp \left(-0.29353 Z^{3}+0.63508 Z^{2}+4.1778 Z+0.31688\right), \\
{[-]} \\
Z=\frac{1000}{T}-1,[-]
\end{gathered}
$$

Although this SRE kinetics model is a combination of different experiments, both were investigated on Ni-based catalysts and the results in the study of De-Souza et $a .^{15}$ satisfied these models.

Model B. This alternative model was developed by Mas et al. ${ }^{17}$, who studied the kinetics of SRE and derived their own kinetic model. Their model involved four reactions, as follows.

$$
\begin{gathered}
\text { EDC: } \mathrm{C}_{2} \mathrm{H}_{5} \mathrm{OH} \rightarrow \mathrm{CH}_{4}+\mathrm{CO}+\mathrm{H}_{2} \\
\text { EDC/S: } \mathrm{C}_{2} \mathrm{H}_{5} \mathrm{OH}+\mathrm{H}_{2} \mathrm{O} \rightarrow \mathrm{CH}_{4}+\mathrm{CO}_{2}+2 \mathrm{H}_{2} \\
\text { bSMR: } \mathrm{CH}_{4}+\mathrm{H}_{2} \mathrm{O} \rightleftharpoons \mathrm{CO}+3 \mathrm{H}_{2} \\
\text { gSMR: } \mathrm{CH}_{4}+2 \mathrm{H}_{2} \mathrm{O} \rightleftharpoons \mathrm{CO}_{2}+4 \mathrm{H}_{2}
\end{gathered}
$$

The reaction rates of these SRE reactions are expressed as follows.

$$
\begin{aligned}
& r_{\mathrm{EDC}}=k_{\mathrm{EDC}} K_{\mathrm{EtOH}} p_{\mathrm{EtOH}} \frac{1}{\mathrm{DEN}} \\
& r_{\mathrm{EDC} / \mathrm{S}}=k_{\mathrm{EDC} / \mathrm{s}} K_{\mathrm{EtOH}} K_{\mathrm{H}_{2} \mathrm{O}} p_{\mathrm{EtOH}} p_{\mathrm{H}_{2} \mathrm{O}} \frac{1}{\mathrm{DEN}^{2}} \\
& r_{\mathrm{bSMR}}=k_{\mathrm{bSMR}} K_{\mathrm{CH}_{4}} K_{\mathrm{H}_{2} \mathrm{O}}\left(p_{\mathrm{CH}_{4}} p_{\mathrm{H}_{2} \mathrm{O}}-\frac{p_{\mathrm{H}_{2}}{ }^{3} p_{\mathrm{CO}}}{K_{\mathrm{bSMR}}}\right) \frac{1}{\mathrm{DEN}^{2}}
\end{aligned}
$$




$$
r_{\mathrm{gSMR}}=k_{\mathrm{gSMR}} K_{\mathrm{CH}_{4}} K_{\mathrm{H}_{2} \mathrm{O}}\left(K_{\mathrm{H}_{2} \mathrm{O}} p_{\mathrm{CH}_{4}} p_{\mathrm{H}_{2} \mathrm{O}}{ }^{2}-\frac{p_{\mathrm{H}_{2}}{ }^{4} p_{\mathrm{CO}_{2}}}{K_{\mathrm{gSMR}}}\right) \frac{1}{\mathrm{DEN}^{3}}
$$

$$
\mathrm{DEN}=1+K_{\mathrm{EtOH}} p_{\mathrm{EtOH}}+K_{\mathrm{H}_{2} \mathrm{O}} p_{\mathrm{H}_{2} \mathrm{O}}+K_{\mathrm{CH}_{4}} p_{\mathrm{CH}_{4}}
$$

The rate constants of reaction $\mathrm{i}$ are defined as follows.

$$
\begin{aligned}
k_{\mathrm{EDC}}= & 4.833 \times 10^{-4} \exp \left[\frac{-278740}{R}\left(\frac{1}{T}-\frac{1}{873}\right)\right], \\
& {\left[\mathrm{kmol} \mathrm{kg}_{\mathrm{cat}}^{-1} \mathrm{~s}^{-1}\right] } \\
k_{\mathrm{EDC} / \mathrm{S}}= & 5.167 \times 10^{-3} \exp \left[\frac{-235060}{R}\left(\frac{1}{T}-\frac{1}{873}\right)\right], \\
k_{\mathrm{bSMR}}= & 1.667 \times 10^{-3} \exp \left[\frac{-123500}{R}\left(\frac{1}{T}-\frac{1}{873}\right)\right], \\
& {\left[\mathrm{kmol} \mathrm{kg}_{\mathrm{cat}}^{-1} \mathrm{~s}^{-1}\right] } \\
k_{\mathrm{gSMR}}= & 4.000 \times 10^{-3} \exp \left[\frac{-213900}{R}\left(\frac{1}{T}-\frac{1}{873}\right)\right], \\
& {\left[\mathrm{kmol} \mathrm{kg}_{\mathrm{cat}}^{-1} \mathrm{~s}^{-1}\right] }
\end{aligned}
$$

Also, the adsorption equilibrium constants of species $\mathrm{k}$ are expressed as follows.

$$
\begin{aligned}
K_{\mathrm{H}_{2} \mathrm{O}} & =3.691 \times 10^{-4} \exp \left[\frac{92400}{R}\left(\frac{1}{T}-\frac{1}{873}\right)\right],\left[\mathrm{Pa}^{-1}\right] \\
K_{\mathrm{EtOH}} & =6.089 \times 10^{-4} \exp \left[\frac{199700}{R}\left(\frac{1}{T}-\frac{1}{873}\right)\right],\left[\mathrm{Pa}^{-1}\right] \\
K_{\mathrm{CH}_{4}} & =1.120 \times 10^{-2} \exp \left[\frac{124700}{R}\left(\frac{1}{T}-\frac{1}{873}\right)\right],\left[\mathrm{Pa}^{-1}\right]
\end{aligned}
$$

Lastly, the equilibrium constants of reactions, $K_{\mathrm{bSMR}}$ and $K_{\text {gSMR }}$ could be determined according to eqn (27) and (28), respectively.

2.1.2 Kinetics of sorption enhancement (SE). Sorption enhancement by carbonation or $\mathrm{CO}_{2}$ capture reaction is provided to SRE reactions by adding a solid sorbent. Herein, dolomite was chosen as the sorbent. The kinetics of carbonation on dolomite, as defined by Sun et $a l .{ }^{64}$, was added to the models as follows:

$$
r_{\mathrm{carb}}=k_{\mathrm{carb}}\left(p_{\mathrm{CO}_{2}}-p_{\mathrm{CO}_{2}, \mathrm{eq}}\right)^{n} S_{0}\left(1-X_{\mathrm{CaO}}\right)
$$

where the equilibrium pressure of $\mathrm{CO}_{2}\left(p_{\mathrm{CO}_{2}, \mathrm{eq}}\right)$ has two ranges as follows:

(1) For $T>1173.15 \mathrm{~K}$ (Abanades et al. ${ }^{65}$ )

$$
p_{\mathrm{CO}_{2}, \mathrm{eq}}=1.216 \times 10^{12} \exp \left[\frac{-19130}{T}\right]
$$

(2) For $T \leq 1173.15 \mathrm{~K}$ (Johnsen et al. ${ }^{32}$ )

$$
p_{\mathrm{CO}_{2}, \mathrm{eq}}=4.1918 \times 10^{12} \exp \left[\frac{-20474}{T}\right]
$$

The rate constant of carbonation $\left(k_{\mathrm{carb}}\right)$ and the degree of partial pressure $(n)$ depend on the amounts of $\mathrm{CO}_{2}$ as follows.

(1) For $\left(p_{\mathrm{CO}_{2}}-p_{\mathrm{CO}_{2}, \mathrm{eq}}\right)>10000 \mathrm{~Pa}$

$$
k_{\text {carb }}=1.04 \times 10^{-6} \exp \left[\frac{-20400}{R T}\right],\left[\mathrm{kmol} \mathrm{m}^{-2} \mathrm{~s}^{-1}\right]
$$

$n=0$

(2) For $0<\left(p_{\mathrm{CO}_{2}}-p_{\mathrm{CO}_{2}, \mathrm{eq}}\right) \leq 10000 \mathrm{~Pa}$

$$
k_{\text {carb }}=1.04 \times 10^{-10} \exp \left[\frac{-20400}{R T}\right],\left[\mathrm{kmol} \mathrm{m}^{-2} \mathrm{~Pa}^{-1} \mathrm{~s}^{-1}\right]
$$

$n=1$

If $\left(p_{\mathrm{CO}_{2}}-p_{\mathrm{CO}_{2}, \text { eq }}\right) \leq 0 \mathrm{~Pa}, \mathrm{CO}_{2}$ is released via decarbonation.

\subsection{System and properties}

Fig. 1 shows a typical design of the riser according to Kunii and Levenspiel. ${ }^{36}$ The riser had an inlet of feed gas at the bottom section, a $0.05 \mathrm{~m}$ diameter channel for the inlet solid at the right, and an outlet for the mixture at the top. The channel of the inlet solid was $0.075 \mathrm{~m}$ above the bottom. The feed gas included EtOH and steam, while the inlet solid included two individual phases, namely, catalyst phase and sorbent phase. The SRE was performed with the catalyst phase, while the carbonation was performed with the sorbent phase. For the catalyst phase, the Ni-based catalyst properties were set and assumed to have uniform size and density. For the sorbent phase, the feed sorbent was fresh dolomite, whose properties were set and assumed to be uniform. The fresh dolomite was assumed to contain $60 \% \mathrm{CaO}$ and $40 \%$ of $\mathrm{MgO}$ by weight. The properties for each solid phase are presented in Table S3. $\dagger$

SESRE would benefit from operating in this CFBR system if the results from the chosen system satisfied these constraints/ goals: (1) no solid accumulation in the riser; (2) the effluent gas should contain high $\mathrm{H}_{2}$ purity (about 94-96\%) on a dry basis as a packed-bed reactor and achieve equilibrium, ${ }^{18}$ while the $\mathrm{H}_{2}$ flux should be as high as possible; and (3) CaO conversion $\left(X_{\mathrm{CaO}}\right)$ at the solid outlet should be lower than $28 \%$, which is the stable maximum capacity of dolomite after steady re-cycling. ${ }^{32}$

\subsection{Simulation method and analysis}

The 2D geometry of the riser and its different computational domains, as shown in Fig. 1, was drawn by ANSYS ${ }^{\circledR}$ DesignModeler ${ }^{\mathrm{TM}}$. The domains were meshed uniformly by ANSYS ${ }^{\circledR}$ Meshing $^{\mathrm{TM}}$ with four different cell sizes for mesh refinement. Then, the models were calculated in the domains via ANSYS ${ }^{\circledR}$ Fluent®. The kinetic rates of SRE and carbonation were derived to be compatible in Fluent ${ }^{\circledR}$ by writing in C-language user 


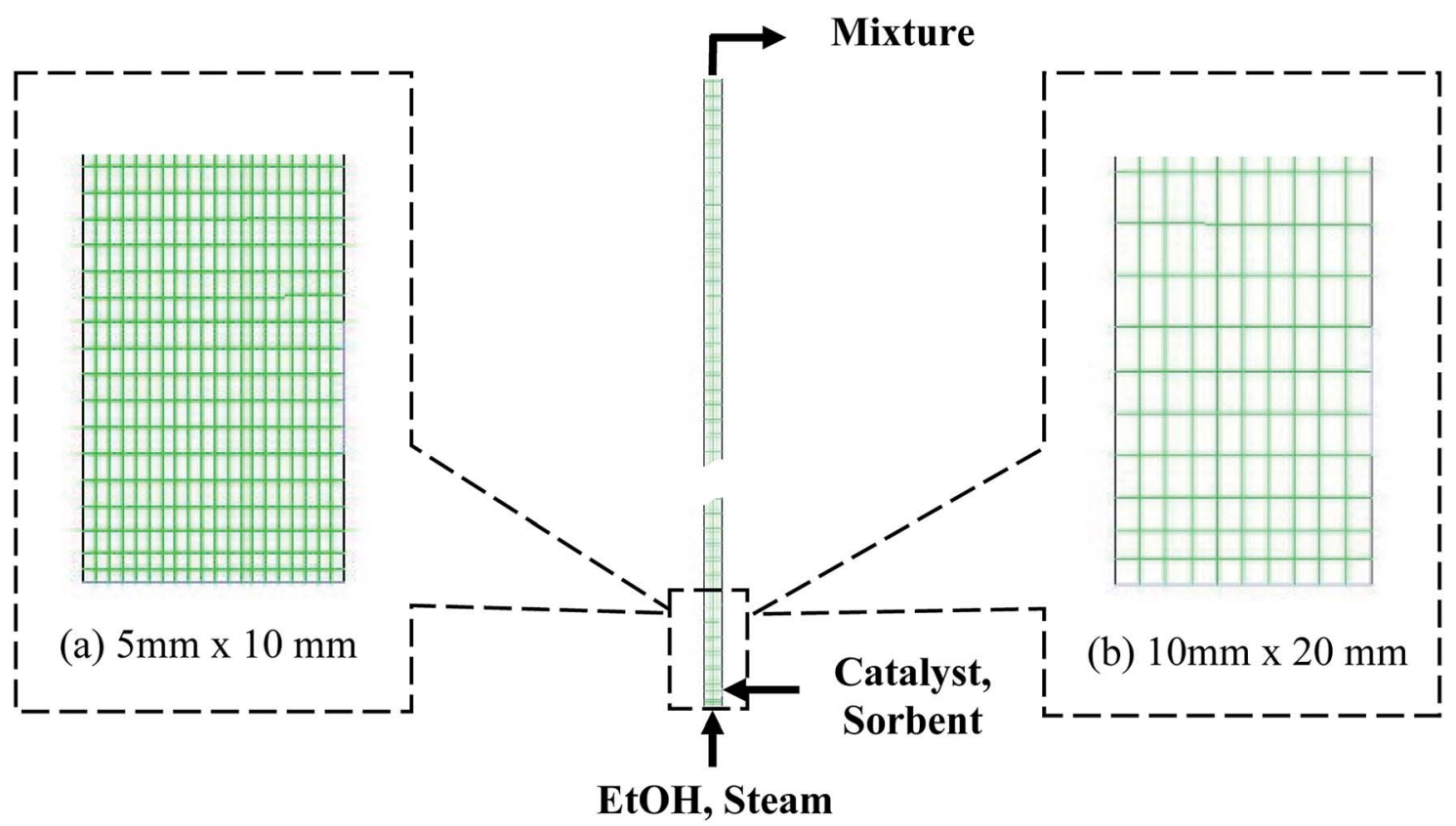

Fig. 1 The system of the riser and the meshes with different cell sizes of the domain: (a) the smallest size and (b) the largest size.

define functions (UDFs). These rates were compiled and returned values as volumetric rates. The calculations were transient for $20 \mathrm{~s}$ of operation with a time step of $1 \times 10^{-3} \mathrm{~s}$. Initially, there was only inert $\mathrm{N}_{2}$ in the domain. All the gas and solid feeds entered through their inlet boundaries in the normal direction and were input in the form of velocities and volume fractions of each phase but with the same temperature. The wall surface was set as no-slip and under adiabatic conditions. The effluent gas was discharged to the atmosphere. The other phase and system properties were set as shown in Table S3. $\dagger$

Because there were many parameters that could mutually affect the system performance of $\mathrm{H}_{2}$ production, a statistical method, such as $2^{k}$ full factorial design, was applied to analyze the significance of each single parameter (main effect) and their interactions were studied via analysis of variance (ANOVA). The five concerning parameters were sufficiently chosen for analyses with 32 runs of simulation. The studied parameters included design parameters (the gas inlet velocity, the solid flux, and the diameter of riser) and reaction parameters (the catalyst-tosorbent ratio and the temperatures of the inlets). Two levels of these parameters and other system properties are shown in Table S4. $\uparrow$ The $\mathrm{H}_{2}$ flux and the $\mathrm{H}_{2}$ purity, which represented the performance of $\mathrm{H}_{2}$ production, were chosen as the response variables in ANOVA. The regression models from ANOVAs can help optimizing the values of the parameters that give the best performance of SESRE in this CFBR system.

\section{Results and discussion}

\subsection{Model validations}

There were two sections of validations performed in this study: cold flow validation and hot flow validation. The cold flow validation was performed to test all the chosen hydrodynamic models listed in Tables S1 and S2. $\dagger$ In hot flow validation, the
UDFs of the kinetic rates were compiled into simulations to test the chosen kinetic models.

3.1.1 Cold flow validation. The cold flow validation in this study compared the bed heights of the bubbling bed to those obtained in the reference experiments conducted by Lin et al. ${ }^{\mathbf{6 6}}$ and the simulations conducted by Sánchez et al. ${ }^{\mathbf{5 0}}$ At the lowest gas velocity ( $\left.0.320 \mathrm{~m} \mathrm{~s}^{-1}\right)$, several small bubbles occurred and dispersed. When the gas velocity was increased (up to $0.892 \mathrm{~m} \mathrm{~s}^{-1}$ ), some small bubbles collapsed into larger bubbles and the bed was expanded. The time-averaged bed heights of the bed from these simulations and experiments conducted by Lin et $a l .{ }^{66}$ and from the simulations conducted by Sánchez et $a l .{ }^{50}$ are summarized in Table 1 . These results indicated that all the simulated results were very close to the reference values. Thus, the chosen hydrodynamics models were suitable.

3.1.2 Hot flow validation. Because there was no experiment for SRE/SESRE performed in a fluidized bed reactor to act as a reference for validation, SRE/SESRE was only found to be performed in packed-bed reactors. However, SRE reactions on $\mathrm{Ni}$-based catalysts involve the pathway in which EtOH is converted to $\mathrm{CH}_{4}$ and $\mathrm{CH}_{4}$ is then reformed via SMR reactions. There were some experiments that operated SMR/SESMR in bubbling fluidized bed reactors. Herein, the reaction validation was divided into two sections. In the first section, UDFs for SMR/SESMR were compiled to validate with the experimental results in a bubbling bed reformer, as reported by Johnsen et $a .^{33}$ In the second section, UDFs for SRE/SESRE were compiled to validate with the experimental results in a packedbed reformer, as reported by Olivas et al. ${ }^{18}$

In the SMR/SESMR validations, the SMR kinetic model of Xu and Froment ${ }^{62}$ was used to validate the experimental results reported by Johnsen et $a l .{ }^{33}$, as shown in Table 2 . At first, only the SMR kinetics was compiled for SMR validation. Then, additional carbonation kinetics was employed for SESMR. A 
Table 1 The time-averaged bed heights in the bubbling bed reactor validated with the results of Lin et al. ${ }^{66}$ and Sánchez et al..$^{50}$ with various gas velocities

\begin{tabular}{llll}
\hline & \multicolumn{2}{l}{ Bed height $[\mathrm{m}]$} & \\
\cline { 2 - 3 } & Lin et al. & Sánchez et al. & This study \\
\hline$U=0.320 \mathrm{~m} \mathrm{~s}^{-1}$ & 0.12 & 0.145 & 0.130 \\
$U=0.458 \mathrm{~m} \mathrm{~s}^{-1}$ & 0.15 & 0.160 & 0.155 \\
$U=0.641 \mathrm{~m} \mathrm{~s}^{-1}$ & 0.21 & 0.185 & 0.182 \\
$U=0.892 \mathrm{~m} \mathrm{~s}^{-1}$ & 0.23 & 0.225 & 0.234 \\
\hline
\end{tabular}

comparison of the effluent gas compositions between simulations and the experiments showed that most of them had very good agreement, with only a slight deviation in $\mathrm{CO}$ and $\mathrm{CO}_{2}$ in SMR. It should be noted that although both the kinetic study by $\mathrm{Xu}$ and Froment ${ }^{62}$ and the experiment conducted by Johnsen et al. ${ }^{33}$ were investigated on Ni-based catalysts, but the catalysts were differently synthesized. Differences in the Ni content, structure, and other physicochemical properties could have caused the deviation of the $\mathrm{CO}$ and $\mathrm{CO}_{2}$ compositions.

Table 3 shows SRE/SESRE validations compared with the experimental results and equilibrium, as reported by Olivas et al. ${ }^{18}$ Two different kinetic models were used for SRE: model A, which combined the kinetics model developed by Sun et al. ${ }^{16}$ and that developed by Xu and Froment, ${ }^{62}$ and model B, which used the kinetics model developed by Mas et al. ${ }^{17}$ Next, for SESRE, the carbonation kinetic model was compiled mutually with each SRE model. The results indicated that validations using model A had satisfactory agreement with both the experiments and equilibriums of both SRE and SESRE with only a minor deviation in CO composition, which might be because of the same reason described in the previous paragraph. However, when using model $\mathrm{B}$, the SRE validation showed significant differences in both $\mathrm{CO}$ and $\mathrm{CO}_{2}$ compositions. In addition, SESRE simulation using model $\mathrm{B}$ showed gas compositions exactly the same as the compositions from the SRE simulation and minor carbonation occurred at this operating condition. The drastic deviations in $\mathrm{CO}$ and $\mathrm{CO}_{2}$ compositions and $\mathrm{CO}_{2}$ capture when using model B was because the SRE kinetics developed by Mas et al. ${ }^{17}$ did not involve the WGS reaction, which would have further converted $\mathrm{CO}$ to $\mathrm{CO}_{2}$. Thus, model A was used for investigating the SRE kinetics in this study.

\subsection{Time averaging and mesh refinement}

Because flows and movements in fluidized bed reactors have some fluctuation, time-dependent simulations have to be performed to ensure that the system reaches the quasi-steady state condition. Time-averaged results should be considered from time ranges after the full development. Fig. 2 shows the case of the fluctuation in time dependence from the simulation of run 20 as an example, for which the riser diameter was $0.2 \mathrm{~m}$, inlet temperature was $600{ }^{\circ} \mathrm{C}$, catalyst-to-sorbent ratio was 2.54 $\mathrm{kg} \mathrm{kg}^{-1}$, gas velocity was $4 \mathrm{~m} \mathrm{~s}^{-1}$, and the solid flux was $200 \mathrm{~kg}$ $\mathrm{m}^{-2} \mathrm{~s}^{-1}$. In this case, the $\mathrm{H}_{2}$ flux and area-averaged $\mathrm{H}_{2}$ purity at the exit of the riser were plotted every $0.1 \mathrm{~s}$. And became stable after approximately $3 \mathrm{~s}$. In other runs of this study, the fluctuation stabilized after 3-5 s. Thus, a time-averaged range of 10$20 \mathrm{~s}$ is used with the further simulation results in this study.

In the same example case (run 20), the mesh refinement was investigated through the axial profiles of the time-averaged $\mathrm{H}_{2}$ flux and time- and area-averaged $\mathrm{H}_{2}$ purity with different sizes of cell $(\Delta x \Delta y)$, as displayed in Fig. 3. The results of both the $\mathrm{H}_{2}$ flux and the $\mathrm{H}_{2}$ purity showed that the $10 \mathrm{~mm} \times 20 \mathrm{~mm}$ cell size differed from the others and was not precise. In the case of the area-averaged $\mathrm{H}_{2}$ purity, as shown in Fig. $3 \mathrm{~b}$, the $10 \mathrm{~mm} \times$ $20 \mathrm{~mm}$ cell size fluctuated significantly more than the other sizes with an SD of $1.74-10.09 \%$ for $\mathrm{H}_{2}$ purity $(1.38-8.25 \%$ for the $5 \mathrm{~mm} \times 10 \mathrm{~mm}$ cell size, $1.31-8.23 \%$ for the $10 \mathrm{~mm} \times$ $10 \mathrm{~mm}$ cell size, and $1.34-8.18 \%$ for the $5 \mathrm{~mm} \times 20 \mathrm{~mm}$ cell size). Although the other cell sizes showed good agreement with each other, the $5 \mathrm{~mm} \times 10 \mathrm{~mm}$ size was not chosen because the higher number of cells required additional calculating time. Lastly, the $5 \mathrm{~mm} \times 20 \mathrm{~mm}$ and the $10 \mathrm{~mm} \times 10 \mathrm{~mm}$ cell sizes had the same number of cells, but the $5 \mathrm{~mm} \times 20 \mathrm{~mm}$ size was chosen for further simulations because the radial profiles in the riser clearly had more variances than the axial profiles.

\subsection{Parametric analysis with the $2^{5}$ factorial design}

Table S5 $\dagger$ shows the area-averaged values of the $\mathrm{H}_{2}$ flux, $\mathrm{H}_{2}$ purity, and $\mathrm{CaO}$ conversion near the outlet with a time-average of 10-20 s in all 32 runs. According to the discussion by Johnsen et al. $^{32}$, dolomite has decreased $\mathrm{CaO}$ capacity every cycle, until it steadies to $28 \% \mathrm{CaO}$ conversion. In this study, there was no run in which $\mathrm{CaO}$ conversion reached $28 \%$. Thus, dolomite could be circulated in this CFBR system for SESRE in these ranges of the parameters. Considering the $\mathrm{H}_{2}$ flux and the $\mathrm{H}_{2}$ purity as response variables, the lowest $\mathrm{H}_{2}$ flux $\left(0.0691 \mathrm{~kg} \mathrm{~m}^{-2} \mathrm{~s}^{-1}\right)$ and the lowest $\mathrm{H}_{2}$ purity (56.47\% on a dry basis) occurred in the same run, i.e., run no. 14 . On the contrary, the highest $\mathrm{H}_{2}$ flux was $0.174 \mathrm{~kg} \mathrm{~m}^{-2} \mathrm{~s}^{-1}$ when operated in run 20 , but the $\mathrm{H}_{2}$ purity was only $87.57 \%$ in this case, whereas the highest $\mathrm{H}_{2}$ purity was $94.07 \%$ in run 27 , but the $\mathrm{H}_{2}$ flux dropped to $0.134 \mathrm{~kg} \mathrm{~m}^{-2} \mathrm{~s}^{-1}$. Hence, statistical analysis, such as ANOVA, was used for investigating the best case and for sensitivity analyses. In the

Table 2 The SMR and SESMR validations with the experimental results of Johnsen et al. ${ }^{33}$

\begin{tabular}{llllll}
\hline & & $\mathrm{H}_{2}[\% \mathrm{dry}]$ & $\mathrm{CH}_{4}[\%$ dry $]$ & $\left.\mathrm{CO}_{[} \% \mathrm{dry}\right]$ & $\mathrm{CO}_{2}[\%$ dry $]$ \\
\hline \multirow{2}{*}{ SMR } & Johnsen et al. & $73.4 \%$ & $6.0 \%$ & $8.0 \%$ & $12.0 \%$ \\
& This work & $74.3 \%$ & $6.4 \%$ & $2.7 \%$ & $16.6 \%$ \\
SESMR & Johnsen et al. & $98.0 \%$ & $1.0 \%$ & $0.5 \%$ & $0.5 \%$ \\
& This work & $97.7 \%$ & $1.6 \%$ & $0.4 \%$ & $0.3 \%$
\end{tabular}


Table 3 The SRE and SESRE validations with the experimental results and equilibrium from Olivas et al. ${ }^{18}$

\begin{tabular}{|c|c|c|c|c|c|c|}
\hline & & $\mathrm{H}_{2}[\%$ dry $]$ & $\mathrm{CH}_{4}[\%$ dry $]$ & $\mathrm{CO}[\%$ dry $]$ & $\mathrm{CO}_{2}[\%$ dry $]$ & EtOH [\% dry] \\
\hline \multirow[t]{3}{*}{ SRE } & Olivas et al. & $64.7 \%$ & $0.7 \%$ & $4.6 \%$ & $30.0 \%$ & $0.0 \%$ \\
\hline & Equilibrium & $69.6 \%$ & $3.3 \%$ & $8.3 \%$ & $18.7 \%$ & $0.0 \%$ \\
\hline & Sim. using model B & $62.5 \%$ & $4.2 \%$ & $33.3 \%$ & $0.1 \%$ & $0.0 \%$ \\
\hline \multirow[t]{2}{*}{ SESRE } & Olivas et al. & $96.2 \%$ & $0.0 \%$ & $3.8 \%$ & $0.0 \%$ & $0.0 \%$ \\
\hline & Equilibrium & $94.1 \%$ & $1.8 \%$ & $1.6 \%$ & $2.5 \%$ & $0.0 \%$ \\
\hline
\end{tabular}

ANOVA of the $\mathrm{H}_{2}$ flux and the $\mathrm{H}_{2}$ purity, the riser diameter $\left(i_{\mathrm{d}}\right)$, the inlet temperature $\left(T_{\text {in }}\right)$, the catalyst-to-sorbent ratio $(\mathrm{Cat} / \mathrm{Sb})$, the solid flux $\left(G_{\mathrm{s}}\right)$, the gas velocity $(U)$, the $\mathrm{H}_{2}$ flux, and the $\mathrm{H}_{2}$ purity were coded as A, B, C, D, E, R1, and R2, respectively. Significantly, the main effects and interactions, which had a $P$ value less than $0.05,{ }^{67}$ of both the $\mathrm{H}_{2}$ flux and the $\mathrm{H}_{2}$ purity were descending as sorted by the $F$-values or $P$-values, as shown in Tables S6 and S7.†

As shown in Table $66, \uparrow$ all the main effects had significance to the $\mathrm{H}_{2}$ flux. The catalyst-to-sorbent ratio (C), the solid flux (D), the riser diameter (A), the inlet temperature (B), and the gas velocity (E) were very highly significant, with $P$-values $<0.0001$, in descending order. Furthermore, the most significant interactions were $\mathrm{AD}, \mathrm{DE}$, and $\mathrm{AE}$, with $\mathrm{AD}$ being the most significant. As shown in Table S7, $\dagger$ almost all the main effects had significance on the $\mathrm{H}_{2}$ purity, except for the inlet temperature (B). However, the interactions of the inlet temperature $(\mathrm{AB}, \mathrm{AD}$, $\mathrm{BD}$, and ABD) also had a significant effect on the $\mathrm{H}_{2}$ purity. Moreover, the solid flux (D), the riser diameter (A), the gas velocity (E), and the catalyst-to-sorbent ratio (C), in descending
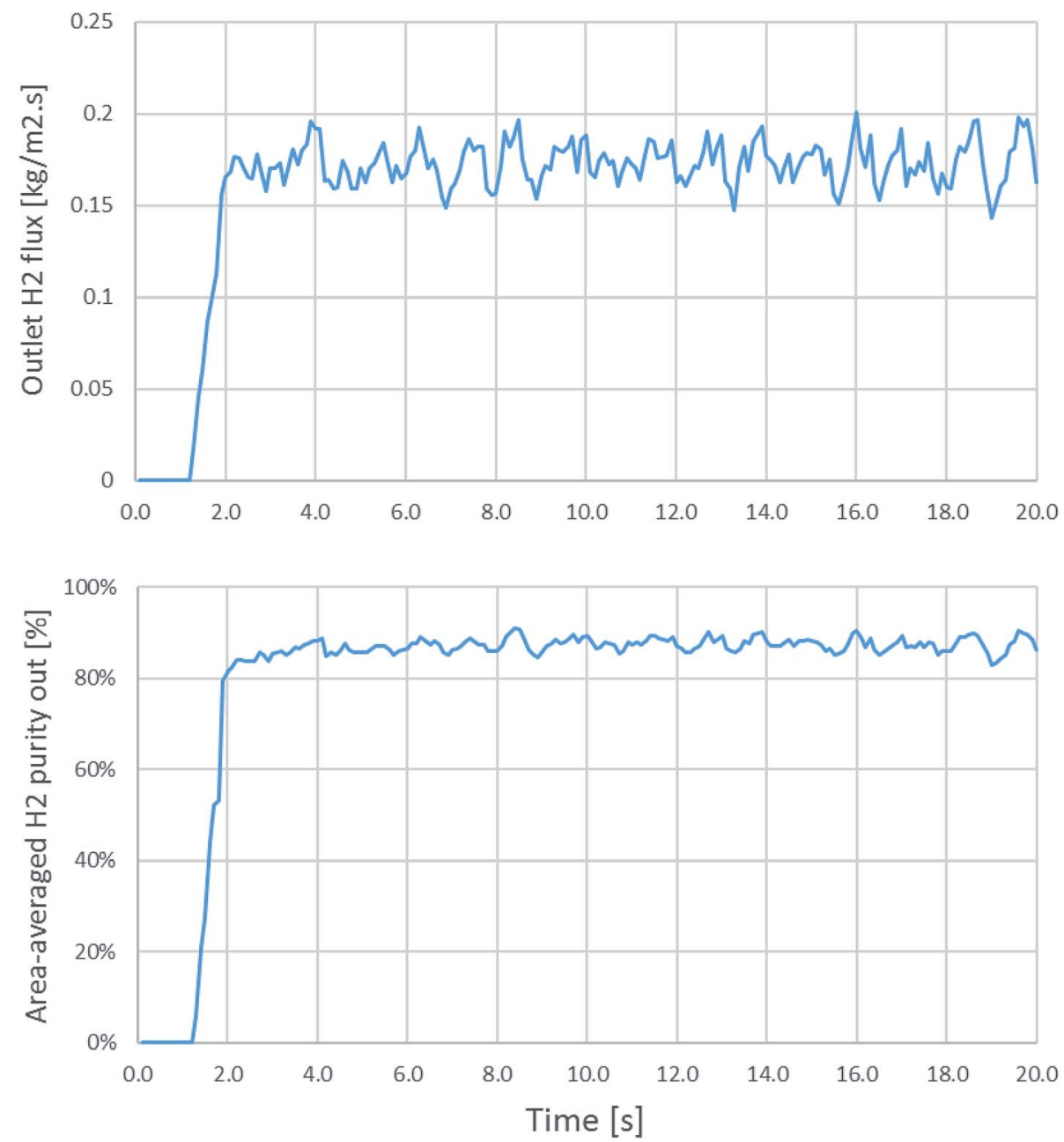

Fig. 2 The outlet $\mathrm{H}_{2}$ flux and the area-averaged $\mathrm{H}_{2}$ purity at the outlet as a function of time in an example case of $i_{\mathrm{d}}=0.2 \mathrm{~m}, T_{\text {in }}=600{ }^{\circ} \mathrm{C}, \mathrm{Cat} / \mathrm{Sb}$ $=2.54, U=4 \mathrm{~m} \mathrm{~s}^{-1}$, and $G_{\mathrm{s}}=200 \mathrm{~kg} \mathrm{~m}^{-2} \mathrm{~s}^{-1}$. 
order, were highly significant, with $P$-values $<0.0001$. These results indicated that the riser diameter (A) and the solid flux (D), both of which are design parameters, were the key parameters for $\mathrm{H}_{2}$ purity in these ranges of the system.

From the ANOVAs, regression models for predicting the $\mathrm{H}_{2}$ flux and the $\mathrm{H}_{2}$ purity were determined using eqn (52) and (53), respectively.

$$
\begin{aligned}
\mathrm{H}_{2} \text { flux }= & 0.126700+0.0095 \mathrm{~A}-0.0083 \mathrm{~B}+0.0134 \mathrm{C} \\
+ & 0.0100 \mathrm{D}+0.0041 \mathrm{E}-0.00468 \mathrm{AD} \\
+ & 0.00353 \mathrm{AE}+0.00362 \mathrm{DE} \\
\mathrm{H}_{2} \text { purity }= & 83.40+3.88 \mathrm{~A}+2.97 \mathrm{C}+4.03 \mathrm{D} \\
& -3.33 \mathrm{E}+1.96 \mathrm{AB}-2.58 \mathrm{AD} \\
& +2.04 \mathrm{BD}-1.92 \mathrm{ABD}
\end{aligned}
$$

where $\mathrm{A}, \mathrm{B}, \mathrm{C}, \mathrm{D}$, and $\mathrm{E}$ in the regression models were coded variables, which transformed low to high levels of the considered parameters in the range from -1 to +1 .

In additions, the sensitivity analyses were performed. The main effects and interactions on the $\mathrm{H}_{2}$ flux and the $\mathrm{H}_{2}$ purity were plotted, as shown in Fig. S1 and S2, $\uparrow$ respectively. The slopes indicate either positive or negative effects on the response variable, while the steepness of each slope as well as the coefficients in the regression models indicate the significant order.

In the case where the $\mathrm{H}_{2}$ flux is the response variable, as shown in Fig. S1a, $\uparrow$ all of the main effects showed a positive trend, except for the inlet temperature (B), according to their coefficients in the regression model. To obtain the most suitable and optimum condition, the catalyst-to-sorbent ratio (C) should be preferably high $\left(2.54 \mathrm{~kg} \mathrm{~kg}^{-1}\right)$, but the inlet temperature (B) should be preferably low $\left(600^{\circ} \mathrm{C}\right)$. Even though SESRE had been found to perform well at around $600-700{ }^{\circ} \mathrm{C},{ }^{18,28}$ SESRE had a breakthrough of sorption enhancement and performed similar to SRE at about $750{ }^{\circ} \mathrm{C}^{28}$ At $700{ }^{\circ} \mathrm{C}$, the sorbent would lose its $\mathrm{CO}_{2}$ capture ability and instead would more closely turn into a decarbonation condition. Hence, the carbonation of $\mathrm{CaO}$, which is an exothermic reaction, prefers operation at a much lower temperature under the breakthrough temperature. The positive direction of the solid flux (D) indicates that the low flux $\left(100 \mathrm{~kg} \mathrm{~m}^{-2} \mathrm{~s}^{-1}\right)$ gave insufficient contact between the feed gas and the catalyst/sorbent particles. Considering the riser diameter (A), the larger diameter leads to a greater $\mathrm{H}_{2}$ flux because the large area of the gas inlet allows for an increased feed, even though the dilute region of the solid might be wider. Finally, an increase in the gas velocity (E) also increased the feed, despite the lower residence time. However, as SESRE has very fast kinetics, it had sufficient time to approach system equilibrium.

Considering the main effects on the $\mathrm{H}_{2}$ purity, as shown in Fig. S2a, $\uparrow$ the solid flux (D), the riser diameter (A), and the catalyst-to-sorbent ratio (C) had positive effects on the $\mathrm{H}_{2}$ purity as well as on the $\mathrm{H}_{2}$ flux. This indicated that at the high levels of these parameters $\left(i_{\mathrm{d}}=0.2 \mathrm{~m}, G_{\mathrm{s}}=200 \mathrm{~kg} \mathrm{~m}^{-2} \mathrm{~s}^{-1}\right.$, and Cat $/ \mathrm{Sb}=$ $2.54 \mathrm{~kg} \mathrm{~kg}^{-1}$ ), the gas-catalyst/sorbent contact was better than at the low levels. Such was the case for the $\mathrm{H}_{2}$ flux, as shown in
Fig. S1a, $\dagger$ which confirmed that a solid flux of $100 \mathrm{~kg} \mathrm{~m}^{-2} \mathrm{~s}^{-1}$ gave lesser amount of catalyst/sorbent to contact with the feed when compared with a solid flux of $200 \mathrm{~kg} \mathrm{~m}^{-2} \mathrm{~s}^{-1}$. Also, the catalyst-to-sorbent ratio of $0.58 \mathrm{~kg} \mathrm{~kg}^{-1}$ had insufficient catalyst to produce more $\mathrm{H}_{2}$, although the reforming was enhanced by $\mathrm{CO}_{2}$ capture. Only the gas velocity (E) had a negative effect on the $\mathrm{H}_{2}$ purity, which was opposed to the $\mathrm{H}_{2}$ flux. This is because higher gas velocity ( $\left.4 \mathrm{~m} \mathrm{~s}^{-1}\right)$ might increase the feed, but the residence time is reduced, leaving it far from SESRE equilibrium.

Fig. S1b and $\mathrm{S} 2 \mathrm{~b} \dagger$ show similar interactions between the solid flux and the riser diameter (AD) and their influence on the $\mathrm{H}_{2}$ flux and the $\mathrm{H}_{2}$ purity, respectively. When the solid flux (D) was considered constant, the lines for the high riser diameter (A+) gave higher values for both the $\mathrm{H}_{2}$ flux and the $\mathrm{H}_{2}$ purity than the lines for the low riser diameter $(\mathrm{A}-$ ). This was because their main effects (A and D) were positive. Thus, at their high levels, they mutually enhanced both the $\mathrm{H}_{2}$ flux and the $\mathrm{H}_{2}$ purity. The slopes of all the lines for the riser diameter (A+ and A-) still had the same positive direction as the main effect (D), but with slight changes in the steepness. This indicated that the interaction (AD) was less effective than the main effects (D), according to their $P$-values listed in Tables $\mathrm{S} 6$ and $\mathrm{S} 7 \dagger$ and their regression coefficients in eqn (52) and (53). However in case of high levels of the solid flux (D+), the more positive effect of the high riser diameter $\left(\mathrm{A}^{+}\right)$over the low riser diameter $(\mathrm{A}-)$ was less than that for the low levels of the solid flux (D-). In other words, when the diameter of riser was larger, the increase in the solid flux was less effective (or less significant) than with the smaller diameter riser. This was in accordance with the small negative regression coefficients of their interaction (AD) in eqn (52) and (53), which decrease the values of both the $\mathrm{H}_{2}$ flux and the $\mathrm{H}_{2}$ purity when both the solid flux and the riser diameter are positive.

Considering the interactions of the gas velocity (E) on the $\mathrm{H}_{2}$ flux, as shown in Fig. S1b and $\mathrm{S} 1 \mathrm{c}, \dagger$ because all of the main effects (A, D, and E) were positive, their interactions (AE and DE) were more positive on the $\mathrm{H}_{2}$ flux. When the solid flux (D) and the riser diameter (A) were at the preferably high, as previously discussed in Fig. S1a, $\uparrow$ and were enhanced with higher gas velocity ( $\mathrm{D}+\mathrm{E}+$ and $\mathrm{A}+\mathrm{E}+$ ), the $\mathrm{H}_{2}$ flux becomes much higher because the increase in the gas velocity increases the feed as well. However, when the riser diameter (A) was the smallest, the interactions with the gas velocity $(\mathrm{A}-\mathrm{E}-$ and $\mathrm{A}-\mathrm{E}+)$ were very close, i.e., it barely affected the $\mathrm{H}_{2}$ flux. This indicated that although the higher gas velocity increases the feed, the residence time would be insufficient if the riser diameter was too small. These very small deviations also indicated that the interactions ( $\mathrm{AE}$ and $\mathrm{DE}$ ) were less effective than the main effects (A and D), corresponding to their high $P$-values in Table $\mathrm{S} 6 \dagger$ and their very small regression coefficients in eqn (52).

Lastly, considering the interaction of the inlet temperature (B) on the $\mathrm{H}_{2}$ purity, as shown in Fig. $\mathrm{S} 2 \mathrm{~b}$ and $\mathrm{S} 2 \mathrm{c}, \dagger$ the line for the high inlet temperature $(\mathrm{B}+)$ crosses the line for the low inlet temperature $(\mathrm{B}-)$ when both interact with the solid flux (D) and the riser diameter (A). This indicates that in this range of inlet temperature $\left(600-700{ }^{\circ} \mathrm{C}\right)$, there was no clear favorite 


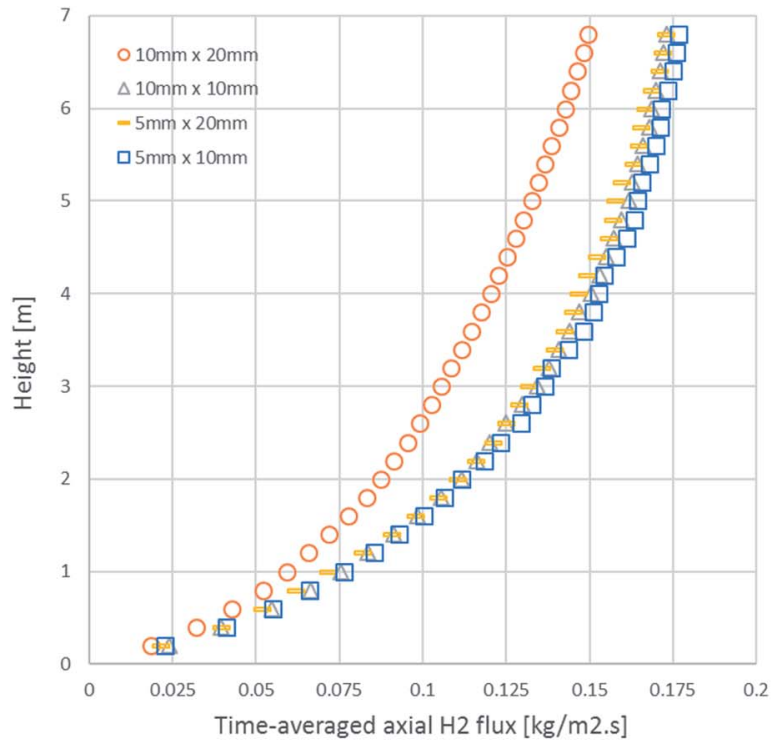

(a) Axial $\mathrm{H}_{2}$ flux

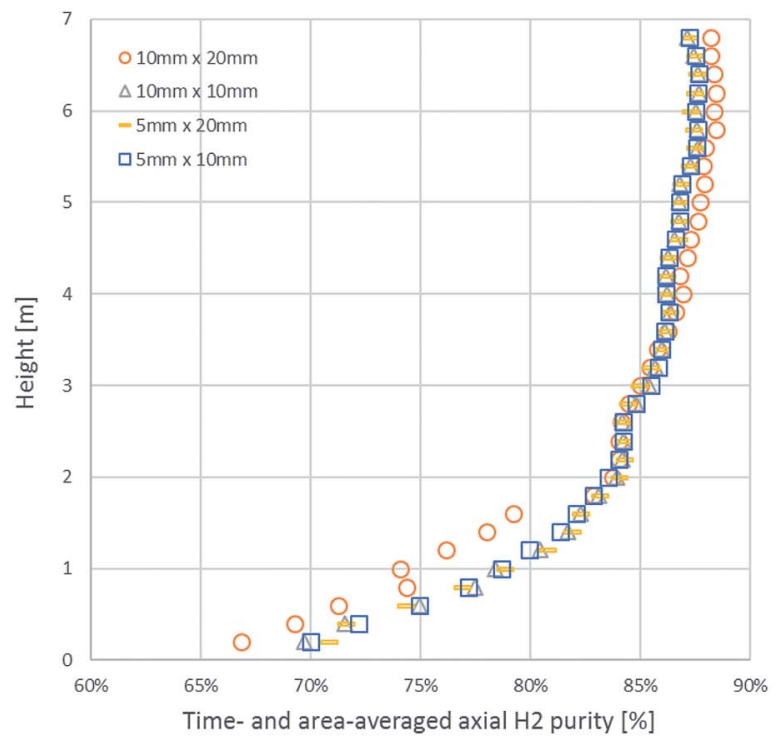

(b) Axial $\mathrm{H}_{2}$ purity

Fig. 3 The axial profiles of: (a) time-averaged $\mathrm{H}_{2}$ flux and (b) the time- and area-averaged $\mathrm{H}_{2}$ purity with different cell sizes in an example case of id $=0.2 \mathrm{~m}, T_{\text {in }}=600^{\circ} \mathrm{C}, \mathrm{Cat} / \mathrm{Sb}=2.54, U=4 \mathrm{~m} \mathrm{~s}^{-1}$, and $G_{\mathrm{s}}=200 \mathrm{~kg} \mathrm{~m}^{-2} \mathrm{~s}^{-1}$.

temperature for obtaining higher $\mathrm{H}_{2}$ purity. Moreover, the minor deviations in the steepness of the interactions $(\mathrm{AD}, \mathrm{BD}$, and $\mathrm{AB}$ ) indicated that these interactions were less effective than the main effects (A and D), consistent with their $P$-values in Table S7 $\uparrow$ and their regression coefficients in eqn (53).

Table 4 shows optimization of the $\mathrm{H}_{2}$ flux from the regression models in eqn (52) prior to optimizing the $\mathrm{H}_{2}$ purity from eqn (53). The maximum $\mathrm{H}_{2}$ purity was predicted to be only $86.53 \%$ on a dry basis, while the $\mathrm{H}_{2}$ flux reached $0.174 \mathrm{~kg} \mathrm{~m}^{-2}$ $\mathrm{s}^{-1}$ in the riser with $0.2 \mathrm{~m}$ diameter, inlet temperature of $600^{\circ} \mathrm{C}$, catalyst-to-sorbent ratio of $2.54 \mathrm{~kg} \mathrm{~kg}^{-1}$, solid flux of $200 \mathrm{~kg} \mathrm{~m}^{-2}$ $\mathrm{s}^{-1}$, and gas velocity of $4 \mathrm{~m} \mathrm{~s}^{-1}$. These results from the prediction conformed very well to the results from the simulation with these values of parameters, i.e., run 20, where the $\mathrm{H}_{2}$ purity and the $\mathrm{H}_{2}$ flux were $87.57 \%$ on a dry basis and $0.174 \mathrm{~kg}$ $\mathrm{m}^{-2} \mathrm{~s}^{-1}$, respectively.

In the case of optimizing the $\mathrm{H}_{2}$ purity prior to optimizing the $\mathrm{H}_{2}$ flux, as shown in Table 5, the maximum $\mathrm{H}_{2}$ purity was predicted to be up to $94.07 \%$ on a dry basis, while the $\mathrm{H}_{2}$ flux dropped to $0.147 \mathrm{~kg} \mathrm{~m}^{-2} \mathrm{~s}^{-1}$ in the riser with diameter of $0.2 \mathrm{~m}$, inlet temperature of $627^{\circ} \mathrm{C}$, catalyst-to-sorbent ratio of $2.54 \mathrm{~kg}$ $\mathrm{kg}^{-1}$, solid flux of $200 \mathrm{~kg} \mathrm{~m}^{-2} \mathrm{~s}^{-1}$, and gas velocity of $3 \mathrm{~m} \mathrm{~s}^{-1}$. To confirm the results from the prediction, another case with those values of parameters was simulated in run 33 . However, the predicted $\mathrm{H}_{2}$ purity (94.07\% on a dry basis) did not conform to the $\mathrm{H}_{2}$ purity from the simulation of run 33 (only $88.62 \%$ on a dry basis). Thus, the case of run 33 could not be the optimum case for the $\mathrm{H}_{2}$ purity. In this case, the inlet temperature was predicted to be $627{ }^{\circ} \mathrm{C}$, while the other parameters (the riser diameter, the catalyst-to-sorbent ratio, the solid flux, and the gas velocity) were predicted at their limit. According to the previous discussion about unclear preferred inlet temperature, as shown in Fig. S2b and S2c, $\uparrow$ additional prediction cases were determined for the best case instead of run 33 by changing the inlet temperature to its limits at $600{ }^{\circ} \mathrm{C}$ and $700{ }^{\circ} \mathrm{C}$; both cases match the simulations of run 19 and run 27 , respectively, as shown in Table 6.

According to the results shown in Table 6, there was a deviation in the $\mathrm{H}_{2}$ purity in run 27 , which was predicted to be $97.11 \%$, but simulated as $94.07 \%$ on a dry basis. However, as per the previous point in Table S5, $\dagger$ where run 27 obtained the highest $\mathrm{H}_{2}$ purity among all 32 runs of the simulation, the simulation of run 27 also obtained $\mathrm{H}_{2}$ purity higher than that simulated in run 33 (88.62\% on a dry basis), while the $\mathrm{H}_{2}$ flux $\left(0.134 \mathrm{~kg} \mathrm{~m}^{-2} \mathrm{~s}^{-1}\right)$ was less than that in run $33\left(0.146 \mathrm{~kg} \mathrm{~m}^{-2}\right.$ $\mathrm{s}^{-1}$ ). However, in the case of run 19 , both the predicted $\mathrm{H}_{2}$ flux and the predicted $\mathrm{H}_{2}$ purity well-conformed to the results from the simulation. Furthermore, in case of the simulation of run

Table 4 The maximum $\mathrm{H}_{2}$ flux from the regression models and a simulation

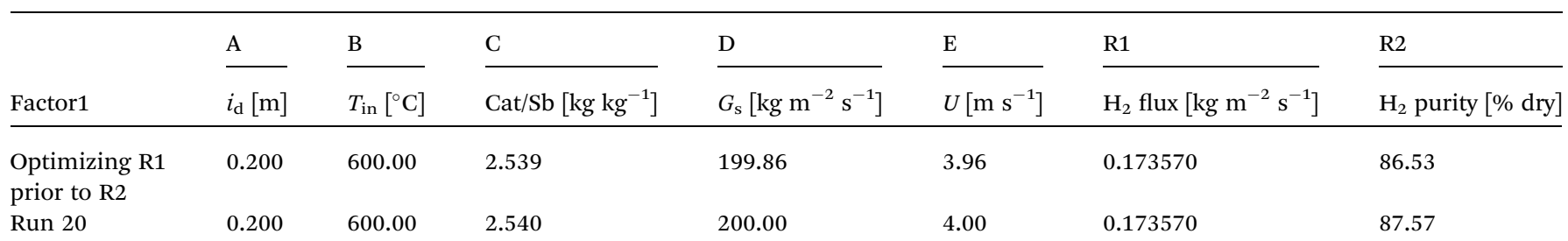


Table 5 The maximum $\mathrm{H}_{2}$ purity from the regression models and a simulation

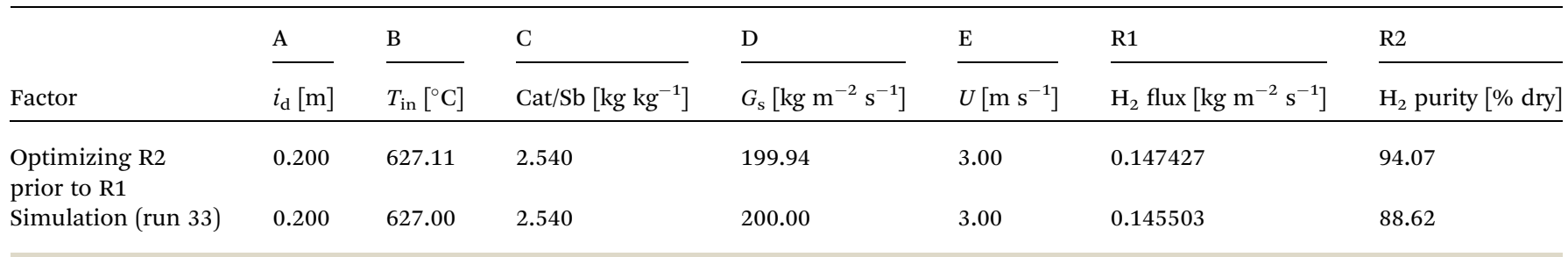

Table 6 The optimum cases from the regression models and simulations

\begin{tabular}{|c|c|c|c|c|c|c|c|}
\hline & A & $\mathrm{B}$ & $\mathrm{C}$ & $\mathrm{D}$ & $\mathrm{E}$ & $\mathrm{R} 1$ & $\mathrm{R} 2$ \\
\hline Factor & $i_{\mathrm{d}}[\mathrm{m}]$ & $T_{\text {in }}\left[{ }^{\circ} \mathrm{C}\right]$ & $\mathrm{Cat} / \mathrm{Sb}\left[\mathrm{kg} \mathrm{kg}^{-1}\right]$ & $G_{\mathrm{s}}\left[\mathrm{kg} \mathrm{m}^{-2} \mathrm{~s}^{-1}\right]$ & $U\left[\mathrm{~m} \mathrm{~s}^{-1}\right]$ & $\mathrm{H}_{2}$ flux $\left[\mathrm{kg} \mathrm{m}^{-2} \mathrm{~s}^{-1}\right]$ & $\mathrm{H}_{2}$ purity [\% dry] \\
\hline Run 27: simulation & 0.200 & 700.00 & 2.540 & 200.00 & 3.00 & 0.133745 & 94.07 \\
\hline Run 19: prediction & 0.200 & 600.00 & 2.540 & 200.00 & 3.00 & 0.151970 & 92.95 \\
\hline Run 19: simulation & 0.200 & 600.00 & 2.540 & 200.00 & 3.00 & 0.146765 & 91.30 \\
\hline
\end{tabular}

19, both the $\mathrm{H}_{2}$ purity and $\mathrm{H}_{2}$ flux $(91.30 \%$ on a dry basis and $0.147 \mathrm{~kg} \mathrm{~m}^{-2} \mathrm{~s}^{-1}$, respectively) were higher than those simulated in run $33\left(88.62 \%\right.$ on a dry basis and $0.146 \mathrm{~kg} \mathrm{~m}^{-2} \mathrm{~s}^{-1}$, respectively). Thus, run 19 might be another candidate for the optimum case in this system.

In an additional consideration, the composition of the effluent gas in the simulations of run 27 and run 19 are shown in Table 7. Here, even the $\mathrm{H}_{2}$ purity of run 27 (which was the highest among all the runs) seemed to reach equilibrium, while EtOH still had not been converted completely compared with the experimental result and the validated result in Table 3, from which the EtOH content should be approximately $0.0 \%$ on a dry basis. This indicated that SESRE could not be performed perfectly in this CFBR system with these ranges of parameters. Moreover, the $\mathrm{CH}_{4}$ content was still high in run 27, while the $\mathrm{CO}$ was still high in run 19. These findings indicated that the reforming reactions of $\mathrm{CH}_{4}$ (SMRs) had not yet reached equilibrium in run 27 , while the shift reaction of CO (WGS) had not yet reached equilibrium in run 19. This was because run 19 achieved both a $\mathrm{H}_{2}$ flux and $\mathrm{H}_{2}$ purity higher than run 33 . Moreover, an additional shift reactor would likely be preferable than applying other effluent gas separation units to purify $\mathrm{H}_{2}$ due to the higher production of $\mathrm{H}_{2}$ in the same time. Thus, run 19 was chosen to be the best case for SESRE operated in this system with these ranges of the parameters.

\subsection{Hydrodynamics in the riser}

With regards to the imperfect performance of SESRE in all cases of the system, considering the hydrodynamics of the best case (run 19) compared with the worst case (run 14) could explain the causes of imperfection more clearly than considering the hydrodynamics of only the best case.

Fig. 4 displays the instantaneous contour plots of the volume fraction of each solid phase (catalyst and sorbent) and gas phase at 10,15 , and $20 \mathrm{~s}$ in run 14 and run 19. The gradient shades of colors from blue to red represent the low volume fraction to high volume fraction of each phase. The contour plots show that both the catalyst and the sorbent particles were in dense clusters in the lower zone (below $2.5 \mathrm{~m}$ height in run 19 and 0.5 $\mathrm{m}$ height in run 14, approximately) of the riser. In the rest of the upper zone of the riser, the solid particles were dense only near the wall and were dilute in the center line (core) of riser in run 19, whereas the solid particles were very dilute in run 14 . The contours of the volume fraction of the solids could explain how in the lower zone of both runs, the bed seemed to be in a turbulent fluidization regime. In contrast, in the upper zone, the bed appeared to be in fast fluidization in run 19 and dilute transportation in run 14 . However, the visual similarity of the volume fraction of the catalyst phase and the sorbent phase indicated good mixing of the catalyst and the sorbent in both runs.

Fig. 5 displays the instantaneous contour plots of the mole fraction of $\mathrm{H}_{2}, \mathrm{EtOH}$, and $\mathrm{CO}_{2}$ in the gas phase at 10, 15, and $20 \mathrm{~s}$ in both run 14 and run 19 . The contour plots in run 19 show that the mole fraction of each component in the gas phase seemed to approach full development from a $2.0 \mathrm{~m}$ height of the riser, which was still located in the dense zone of the bed. However, above this zone to the exit, $\mathrm{H}_{2}$ did not reach

Table 7 The compositions of effluent gas from simulations in the optimum cases

\begin{tabular}{llllll}
\hline & $\mathrm{H}_{2}[\% \mathrm{dry}]$ & $\mathrm{CH}_{4}[\% \mathrm{dry}]$ & $\mathrm{CO}[\% \mathrm{dry}]$ & $\mathrm{CO}_{2}[\%$ dry $]$ & EtOH $[\%$ dry $]$ \\
\hline Run 27 & $94.07 \%$ & $3.87 \%$ & $1.21 \%$ & $0.36 \%$ & $0.49 \%$ \\
Run 19 & $91.30 \%$ & $0.37 \%$ & $7.42 \%$ & $0.61 \%$ & $0.31 \%$
\end{tabular}



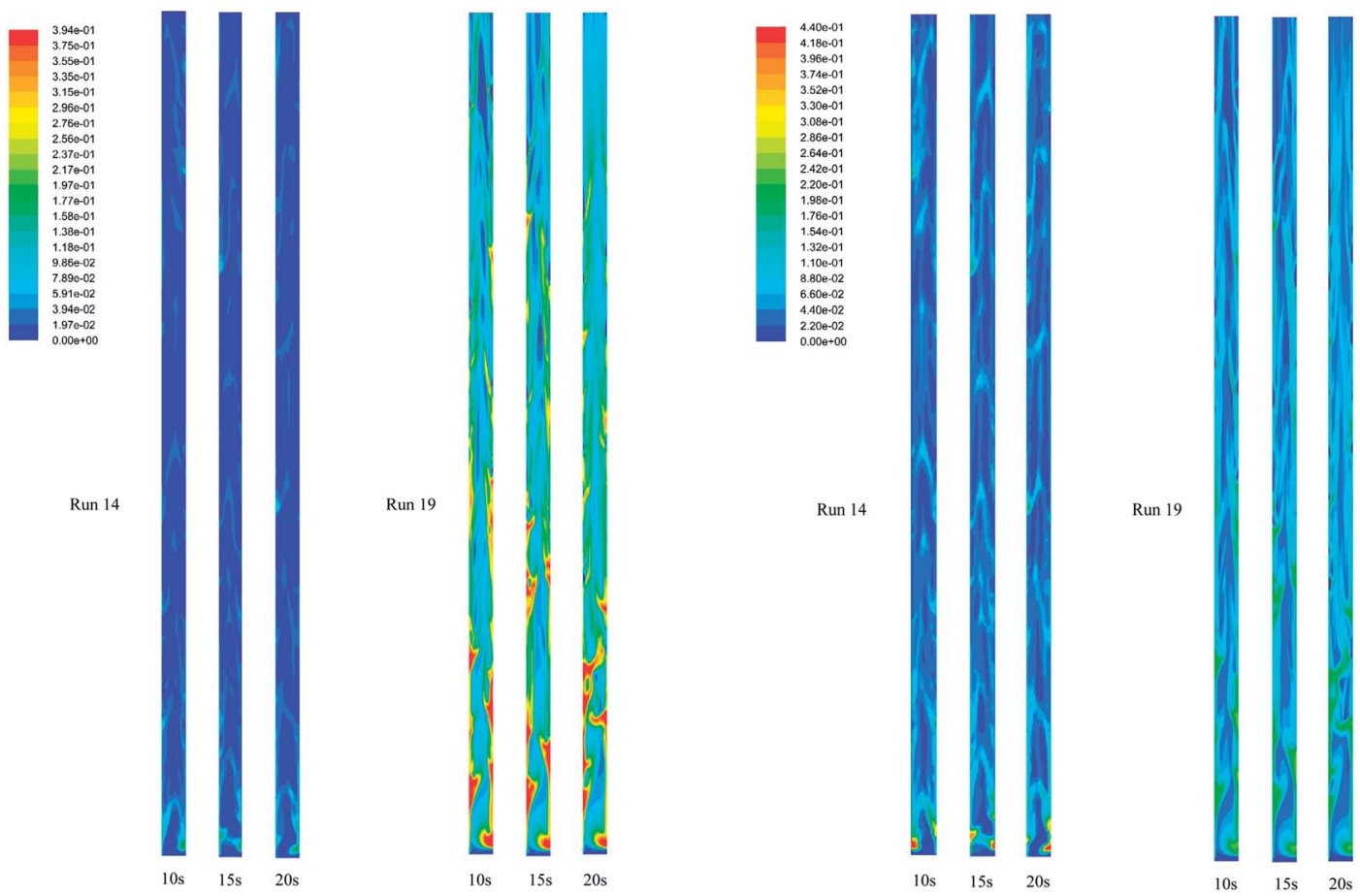

(a) Catalyst

(b) Sorbent
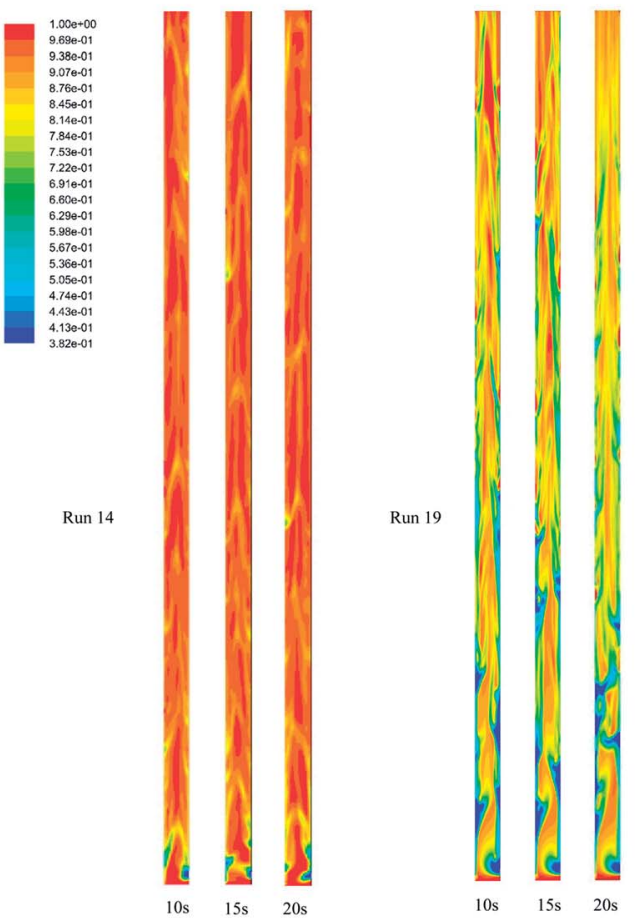

(c) Gas

Fig. 4 The instantaneous volume fraction of each phase at 10, 15, and $20 \mathrm{~s}$ in the best performance case (run 19) and the worst performance case (run 14).

equilibrium in the core of the riser. Also, $\mathrm{EtOH}$ and $\mathrm{CO}_{2}$ were not completely converted and adsorbed in the core. These contours confirmed that SESRE could not be performed perfectly even in the best case of this system. Next, considering the contour plots in run 14, the immediate increase in $\mathrm{H}_{2}$ and $\mathrm{CO}_{2}$ composition and the immediate decrease in EtOH 


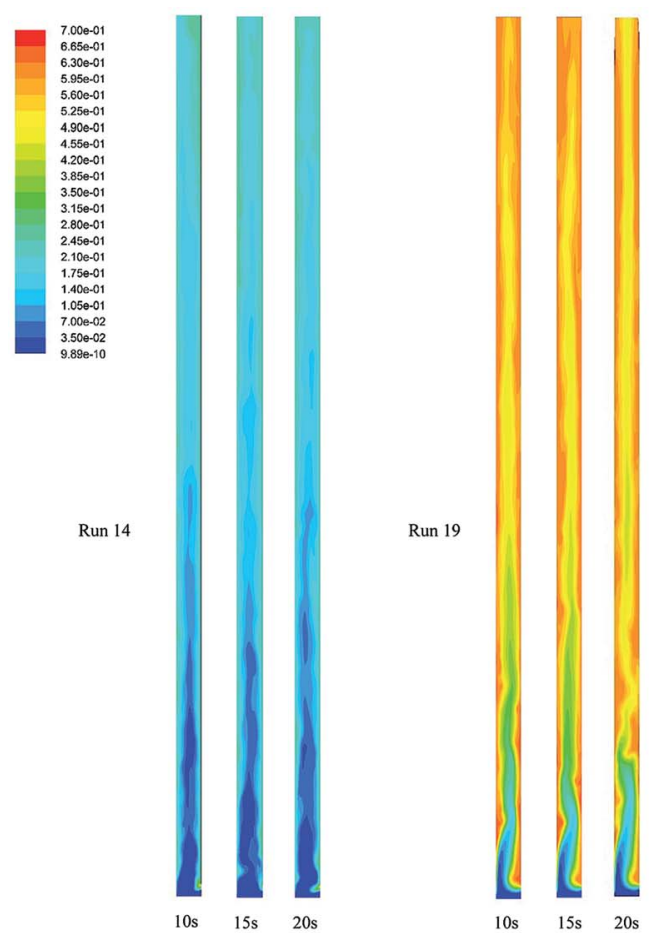

(a) $\mathrm{H}_{2}$

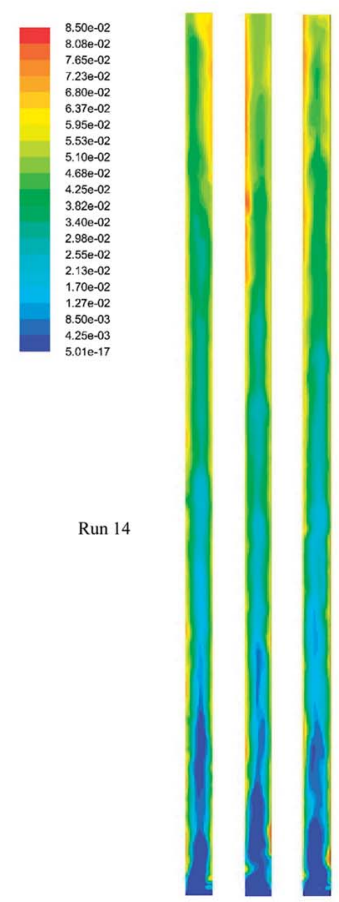

10 s
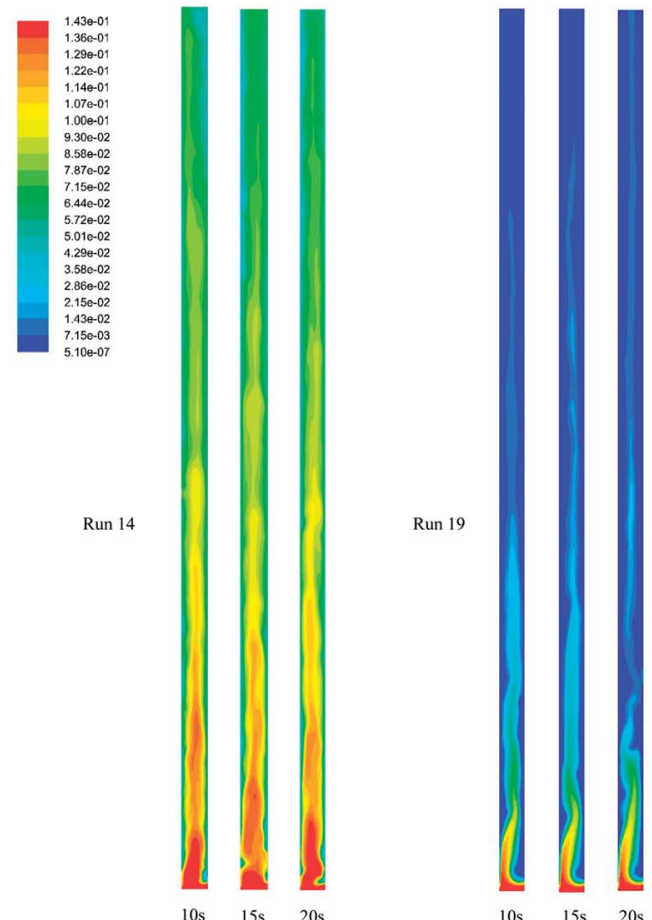

$10 \mathrm{~s}$

$20 \mathrm{~s}$

(b) $\mathrm{EtOH}$

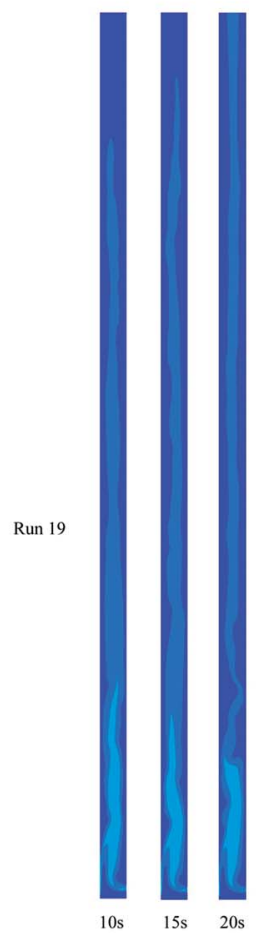

(c) $\mathrm{CO}_{2}$

Fig. 5 The instantaneous mole fraction (wet basis) of (a) $\mathrm{H}_{2}$ (b) $\mathrm{EtOH}$ and (c) $\mathrm{CO}_{2}$ in the gas phase at 10, 15, and $20 \mathrm{~s}$ in the best performance case (run 19) and the worst performance case (run 14).

composition nearly exactly matched with those observed for dense solids, as shown in Fig. 4, within the lower zone (below $0.5 \mathrm{~m}$ height). Above this zone, $\mathrm{H}_{2}$ and $\mathrm{CO}_{2}$ compositions gradually increased, while EtOH composition gradually decreased up to the outlet. The case of $\mathrm{CO}_{2}$ was notable in run 19, where $\mathrm{CO}_{2}$ immediately rose to the highest in the bottom 

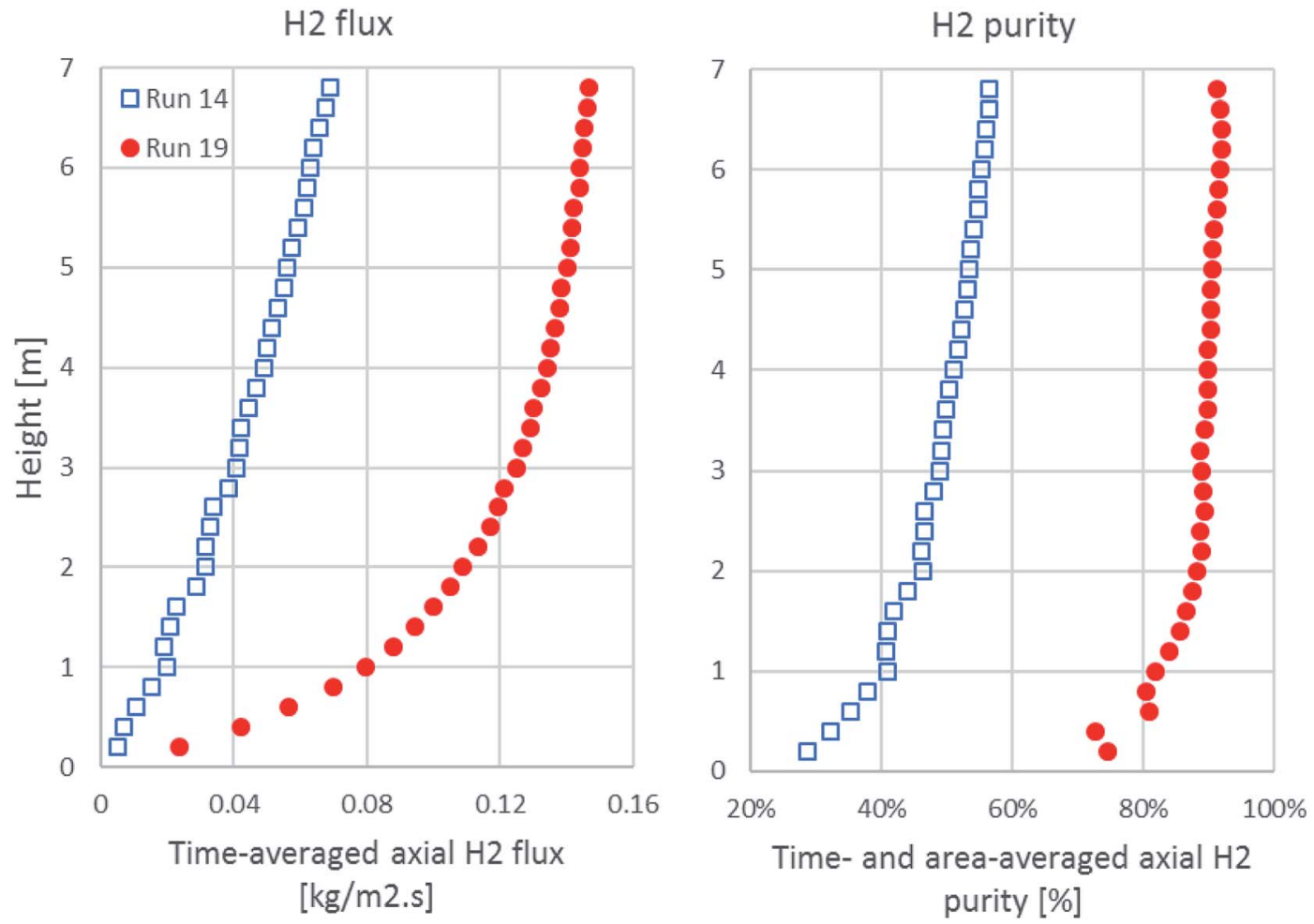

Fig. 6 The axial profiles of time-averaged $\mathrm{H}_{2}$ flux and time- and area-averaged $\mathrm{H}_{2}$ purity in the best performance case (run 19) and the worst performance case (run 14).

core, and then rapidly reduced and remained steady in the upper core. In run $14, \mathrm{CO}_{2}$ immediately rose and gathered at the both sides of the wall, but this did not occur in the core within the lower zone. These core-annulus patterns of $\mathrm{CO}_{2}$ in the bottom half of the riser, which also appeared in the cases of the produced $\mathrm{H}_{2}$, might due to the solid cluster appearance inside the system, as shown in Fig. 4a and b. However, comparing the $\mathrm{CO}_{2}$ fraction along the axial direction in the overview, it can be seen that the $\mathrm{CO}_{2}$ fraction in run 14 increased gradually throughout the riser. On the contrary, the $\mathrm{CO}_{2}$ fraction in run 19 decreased in the bottom zone and then seemed steady in the upper zone. Furthermore, the $\mathrm{CO}_{2}$ fraction in run 14 was higher than that in run 19. The $\mathrm{CO}_{2}$ fraction in run 14 indicated that the continuous increase in $\mathrm{CO}_{2}$ composition in this upper zone could indicate that SRE, which produced $\mathrm{CO}_{2}$, took place rather than the capturing of $\mathrm{CO}_{2}$. In other words, the insufficient amount of sorbent all along the axial direction might have made the $\mathrm{CO}_{2}$ composition increase gradually. Unlike in run 19 , the $\mathrm{CO}_{2}$ fraction occurred higher in the bottom zone because carbonation was a slower reaction than SRE, such that more $\mathrm{CO}_{2}$ was adsorbed until it became steady in the rest of the upper zone. In conclusion, besides the incomplete conversion of $\mathrm{EtOH}$, which was found in both runs but higher in run 14, the lack of sorption enhancement might be another cause for the worst performance of run 14 .

Next, the catalyst and sorbent distributions along the axial and radial directions were expected to be key hydrodynamics parameters to explain the performance of SESRE in this riser system. Inside the riser of both runs, the volume fraction of both the catalyst and sorbent phase and the volumetric catalystto-sorbent ratio were compared for the $\mathrm{H}_{2}$ flux and the $\mathrm{H}_{2}$ purity as follows.

As shown in Fig. 6, the time-averaged $\mathrm{H}_{2}$ flux and the timeand area-averaged $\mathrm{H}_{2}$ purity in the axial direction are plotted from $0.1 \mathrm{~m}$ height, which was the exact height above the solid inlet channel. The $\mathrm{H}_{2}$ flux of run 19 accumulated rapidly in the lower zone and approached its maximum at the outlet, while the $\mathrm{H}_{2}$ flux of run 14 increased gradually all along the axial direction. The $\mathrm{H}_{2}$ purity of run 19 increased suddenly to about $70 \%$ on a dry basis from the height above the solid inlet, but the $\mathrm{H}_{2}$ purity of run 14 started at about $30 \%$ on a dry basis. Then, the $\mathrm{H}_{2}$ purity of run 19 increased more within the lower zone and slightly increased in the upper zone, while the $\mathrm{H}_{2}$ purity of run 14 increased gradually. These increasing profiles of the $\mathrm{H}_{2}$ flux and the $\mathrm{H}_{2}$ purity were in accordance with the contour of the $\mathrm{H}_{2}$ fraction, as shown in Fig. 5a.

Fig. 7 shows the time- and area-averaged radial profiles of the $\mathrm{H}_{2}$ flux at the outlet of the riser. The radial distance at $0.0 \mathrm{~m}$ was the position of the left wall and that at $0.2 \mathrm{~m}$ was the position of the right wall. In both runs, the $\mathrm{H}_{2}$ flux near both wall sides tended to be almost zero, while the $\mathrm{H}_{2}$ flux was the highest in the core of the riser. Both the $\mathrm{H}_{2}$ flux profiles were almost symmetric and also similar to a typical developed velocity profile of a viscous fluid in an internal pipe.

Fig. 8 shows the time-averaged radial distributions of $\mathrm{H}_{2}$ purity at different heights with the solid inlet on the right side at 0.05-0.10 m height. Each $\mathrm{H}_{2}$ purity profile in run 14 looked similar to the $\mathrm{H}_{2}$ purity profile in run 19 at the same height but 


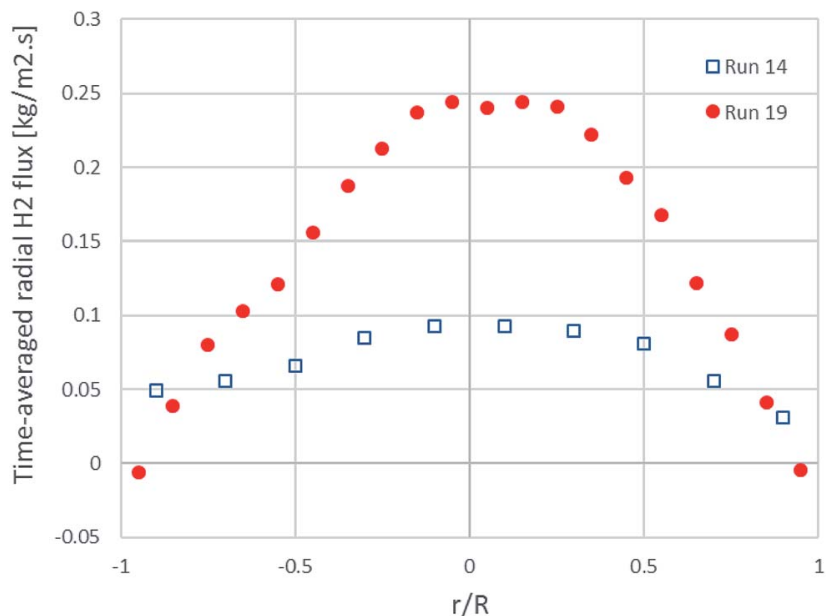

Fig. 7 The time-averaged radial profiles of $\mathrm{H}_{2}$ flux at the outlet in the best performance case (run 19) and the worst performance case (run 14).

had less purity. At exactly above the solid inlet ( $0.1 \mathrm{~m}$ height) in both runs, the $\mathrm{H}_{2}$ purity reached its maximum immediately at the solid inlet on the right wall. Further, the $\mathrm{H}_{2}$ purity decreased along the left direction far from the solid inlet, and then increased near the left wall. At $1.0 \mathrm{~m}$ height and above, the profiles in both runs were almost symmetric to the radial $\mathrm{H}_{2}$ flux profiles in Fig. 7. Considering the development of the $\mathrm{H}_{2}$ purity profile at every height, particularly in the core of the riser, the $\mathrm{H}_{2}$ purity in run 14 was gradually higher, while the $\mathrm{H}_{2}$ purity in run
19 rapidly increased above $1.0 \mathrm{~m}$ height. This increase in the $\mathrm{H}_{2}$ purity in both runs conformed to the axial $\mathrm{H}_{2}$ purity profiles, as shown in Fig. 6. The $\mathrm{H}_{2}$ purity profiles between $6.0 \mathrm{~m}$ and $6.9 \mathrm{~m}$ heights of both runs were almost similar. Near the exit $(6.9 \mathrm{~m}$ height) in both runs, the $\mathrm{H}_{2}$ purity still dropped slightly in the core, conforming to the contour of the $\mathrm{H}_{2}$ fraction in Fig. 5a.

As shown in Fig. 6-8, both the $\mathrm{H}_{2}$ flux and the $\mathrm{H}_{2}$ purity could be further developed to obtain slightly higher results on using a riser with height over $7 \mathrm{~m}$. However, in additional simulations with a $10 \mathrm{~m}$ high riser, there were some cases where the solids accumulated in the riser and then caused errors in those simulations. Thus, the extent height of the riser over $7 \mathrm{~m}$ did not lead to better advantage for operating SESRE in this system.

Because SESRE is a very rapid reaction, solid distribution and mixing of the catalyst and the sorbent might be the cause for SESRE not performing perfectly as per the previous discussion. Fig. 9 shows the time- and area-averaged axial profiles of the volume fraction of the solid phases in both runs. First, in run 19 , the amount of catalyst, sorbent, and total solids were dense in the lower zone (the volume fraction of total solids was about $0.25-0.30$ ). In the upper zone, all the volume fractions of each solid continuously decreased up to the exit and the volume fraction of total solids was 0.06-0.20, which was the range for the fast fluidization regime. ${ }^{68}$ Considering the lower zone, this zone could also be divided into an initial acceleration region (0.5-1.5 $\mathrm{m}$ height) and a dense phase region (1.5-2.5 $\mathrm{m}$ height). In the upper zone, the decrease in the total solid volume fraction was in a transition region (not yet down into the dilute transport region). ${ }^{37,69}$ This fluidization could also be called

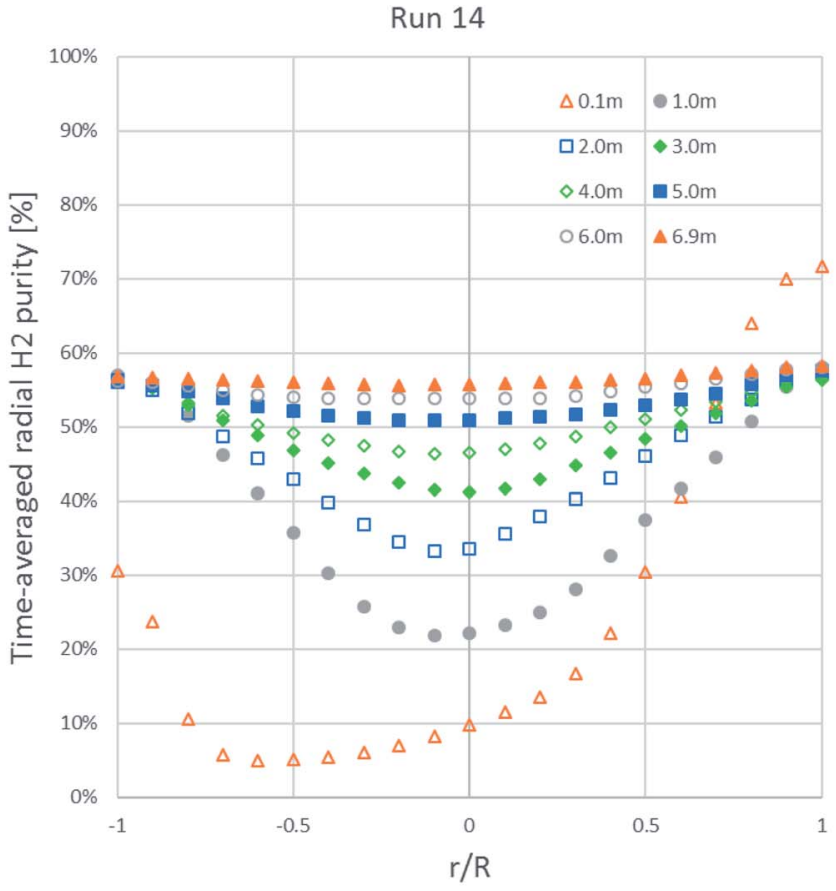

(a) Run 14

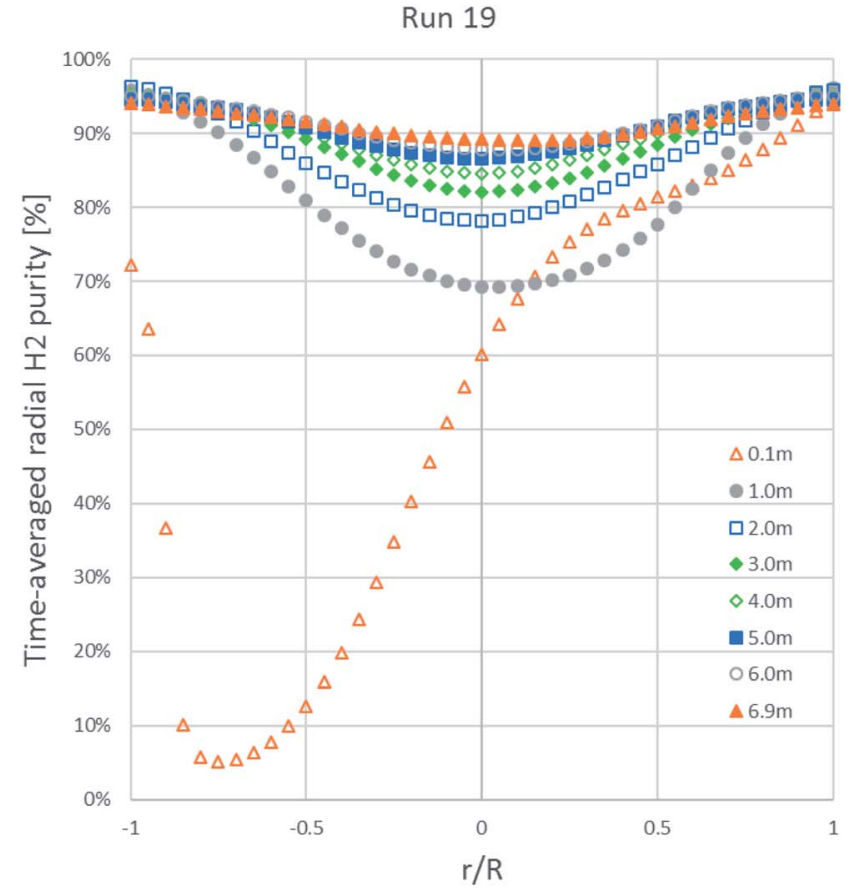

(b) Run 19

Fig. 8 The time-averaged radial profiles of $\mathrm{H}_{2}$ purity at different heights in: (b) the best performance case (run 19) and (a) the worst performance case (run 14) 

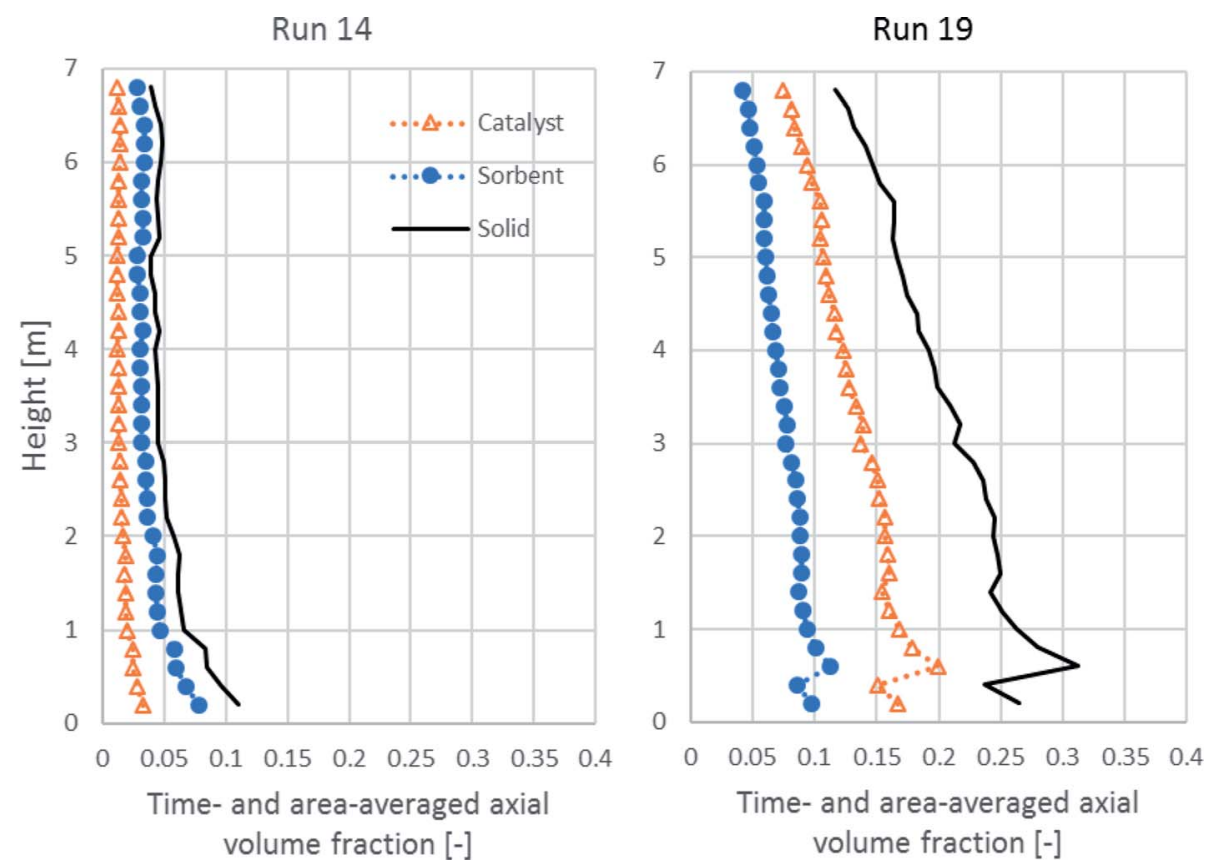

Fig. 9 The time- and area-averaged axial profiles of volume fraction of the solid phases in the best performance case (run 19) and the worst performance case (run 14).

a high-density circulation fluidized bed (HDCFB) system. ${ }^{70}$ Lastly, because the bed was dense in the lower zone (the initial acceleration region and the dense phase region), the axial profile of $\mathrm{H}_{2}$ flux of run 19, as shown in Fig. 6, increased greatly in this lower zone, whereas in run 14 , the total solid was dilute and decreased (volume fraction about 0.10 or less to 0.06 ) in the lower zone, which was not over $1.0 \mathrm{~m}$ height. Then, all along the upper zone, fraction of each solid hardly decreased and the total solid volume fraction was less than 0.06 , which is known as the flow in the dilute transport regime. ${ }^{68}$ The dilute fraction of each solid could cause the gradual increase in the $\mathrm{H}_{2}$ flux in run 14, as discussed in Fig. 6.

As shown in Fig. 10, the time- and area-averaged axial profile of the volumetric catalyst-to-sorbent ratio of each run is plotted for comparing with the ratio with which the solid entered (1.778 $\mathrm{v} / \mathrm{v}$ in run 19 and $0.4085 \mathrm{v} / \mathrm{v}$ in run 14). The results showed that
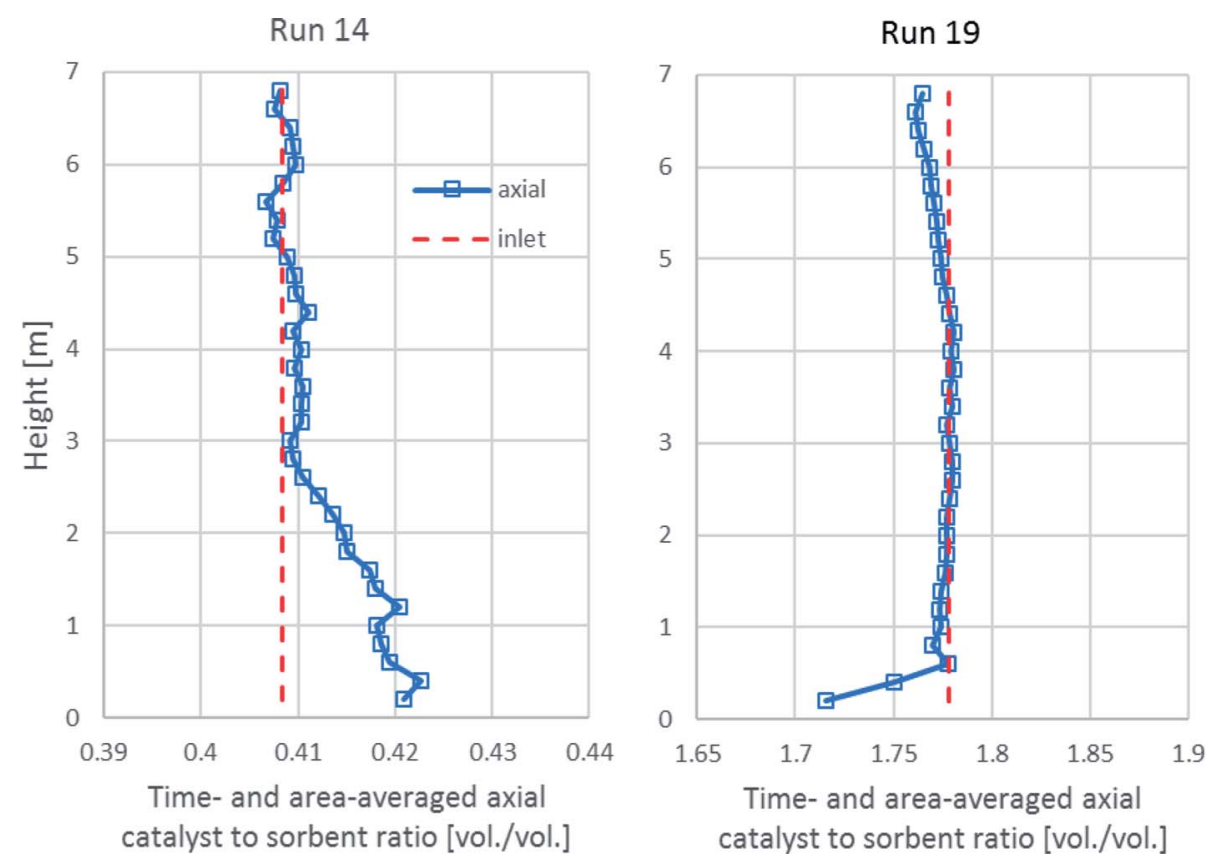

Fig. 10 The time- and area-averaged axial profiles of the volumetric catalyst-to-sorbent ratio in the best performance case (run 19) and the worst performance case (run 14). 


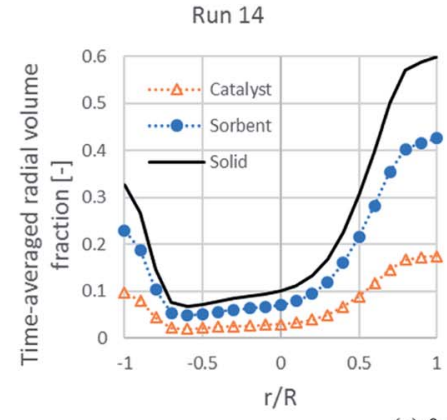

(a) $0.1 \mathrm{~m}$ height
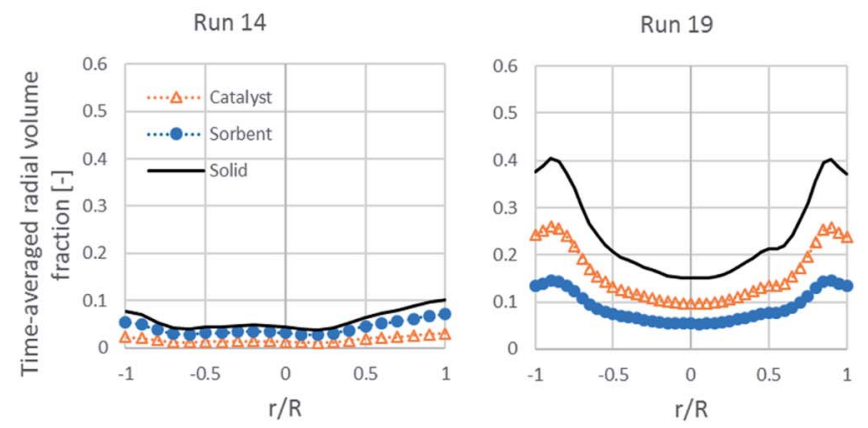

(c) $2.0 \mathrm{~m}$ height
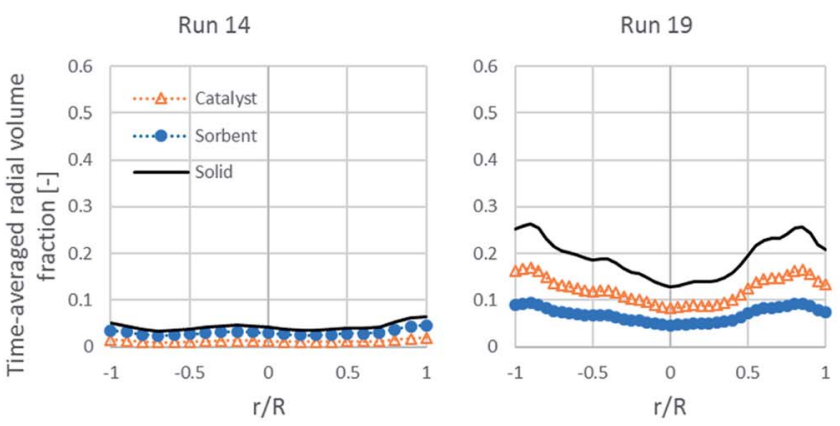

(e) $4.0 \mathrm{~m}$ height
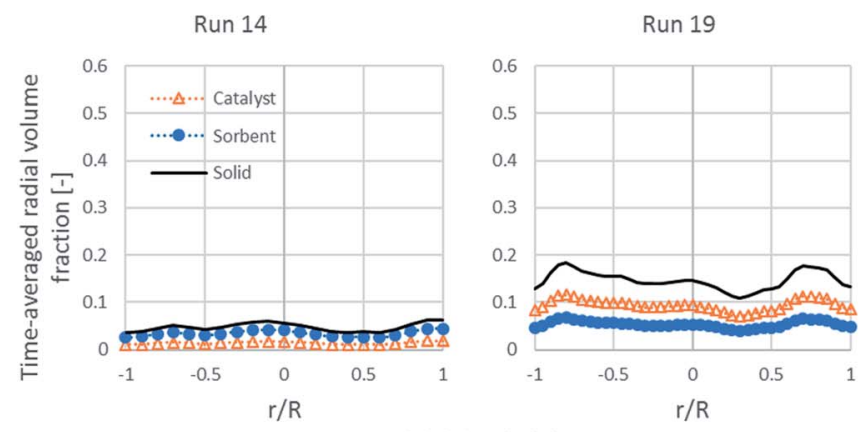

(g) $6.0 \mathrm{~m}$ height
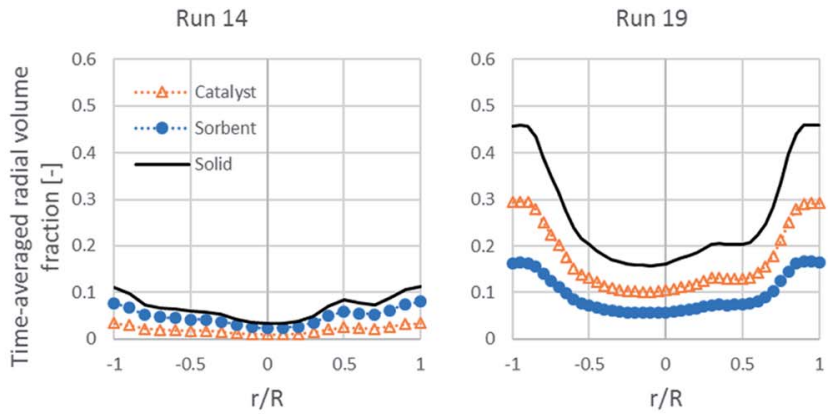

(b) $1.0 \mathrm{~m}$ height
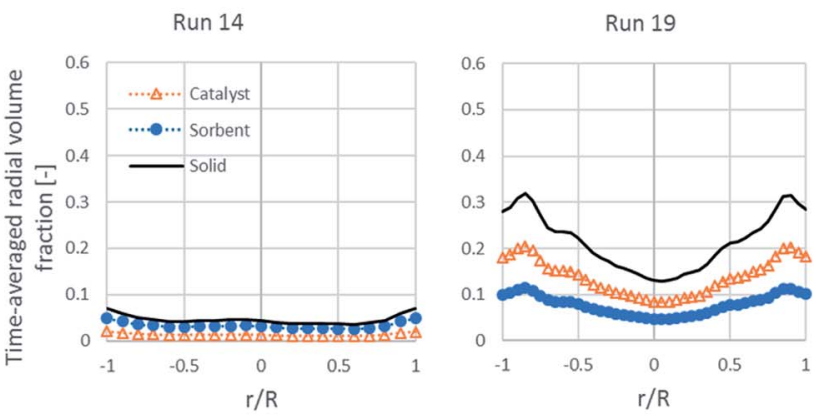

(d) $3.0 \mathrm{~m}$ height
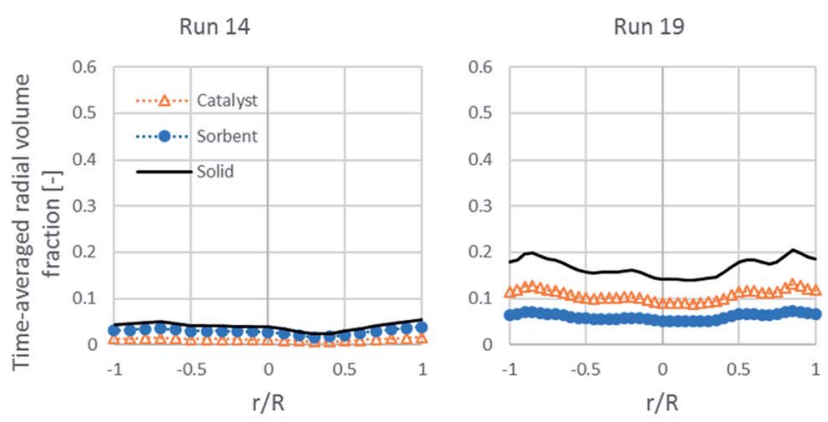

(f) $5.0 \mathrm{~m}$ height
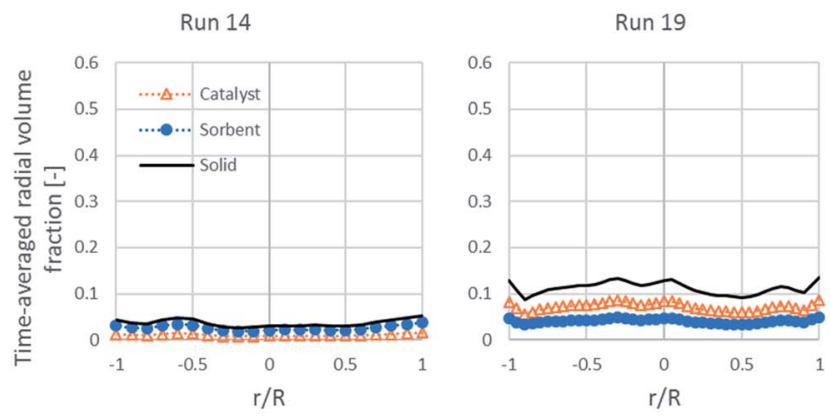

(h) $6.9 \mathrm{~m}$ height

Fig. 11 The time-averaged radial profiles of the volume fraction of the solid phases at different heights in the best performance case (run 19) and the worst performance case (run 14).

after a sufficient height, the ratios in each run nearly equaled each inlet ratio. These results indicated the good mixing between the catalyst and the sorbent, which made the sorption enhancement uniform in the upper zone. Above the entrance of the solid up to $3.0 \mathrm{~m}$ height in run 14, the ratio was slightly higher because the catalyst had higher density $\left(2200 \mathrm{~kg} \mathrm{~m}^{-3}\right)$ than the sorbent (approximately $1540 \mathrm{~kg} \mathrm{~m}^{-3}$ ), so the lighter sorbent was lifted easier than the catalyst. In run 19, the ratio was nearly the same as the inlet ratio almost along the axial direction. However, the lower ratio near the solid entrance might have been affected by the turbulence.

Fig. 11 shows the time-averaged radial profiles of the volume fraction of each solid phase at different heights. At a height over the solid entrance ( $0.1 \mathrm{~m}$ height), the total solids of both runs 

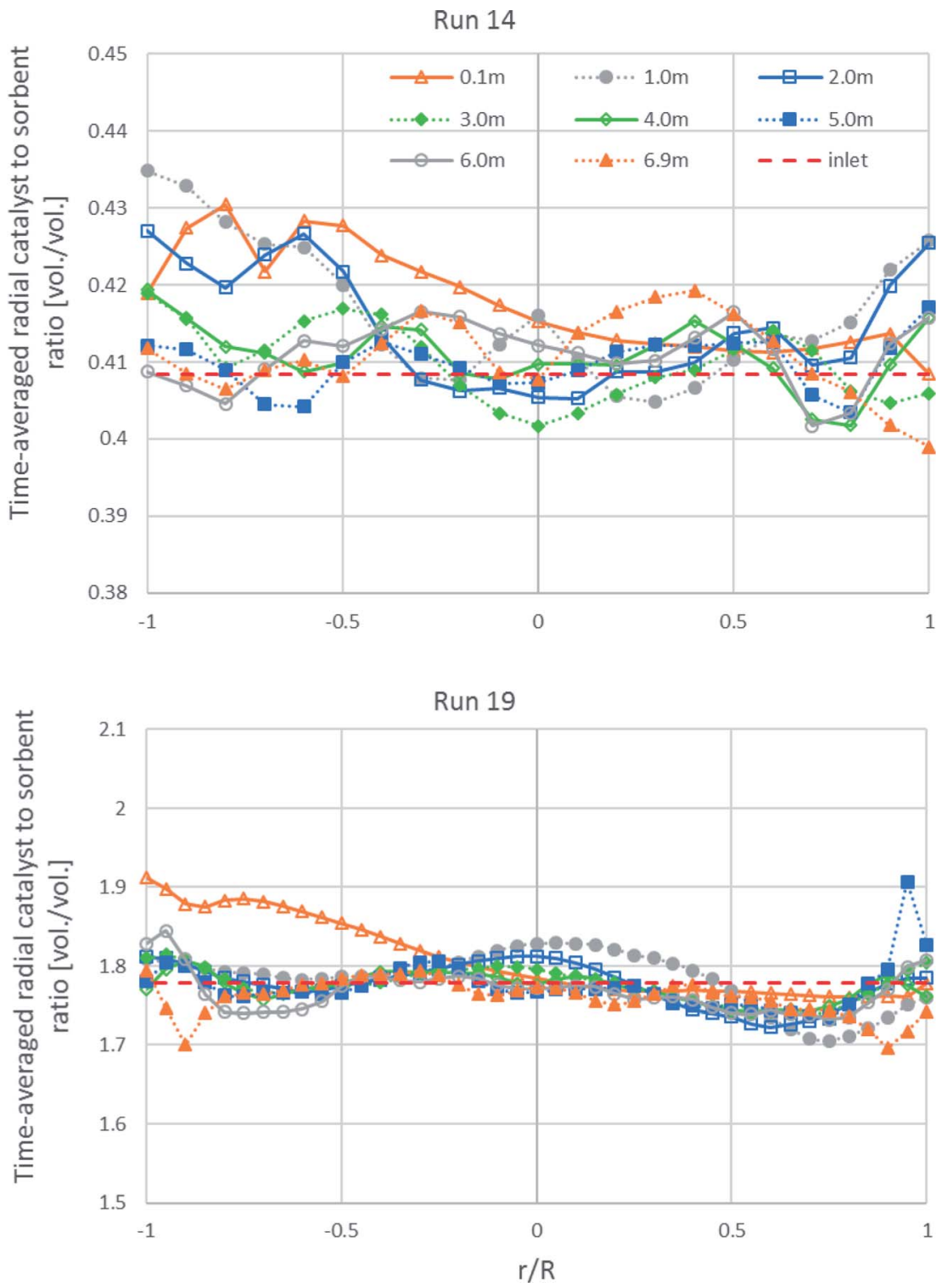

Fig. 12 The time-averaged radial profiles of the volumetric catalyst-to-sorbent ratio at different heights in the best performance case (run 19) and the worst performance case (run 14).

were similarly dense near the solid entrance on the right, but dilute at a distance near the left wall, whereas there was a difference between each run at upper heights. In run 19 at 1.0 $\mathrm{m}$ height, the volume fraction of solids at the right wall rapidly decreased to balance with that at the left wall. At 1.0-4.0 m height, these profiles showed a core-annular flow of fast fluidization. However, the denser bed near both wall sides would be less dense when the bed was blown higher. Up to a height over $6.0 \mathrm{~m}$, the radial distribution was quite uniform. Considering the situation at the core of each height, the bed was very dilute (the total solid volume fraction was about 0.15 and likely to be less) beyond the $1.0 \mathrm{~m}$ height. This was the major cause of the incomplete conversion of EtOH and other intermediates, confirming the results in Table 7 and the contours of run 19 in Fig. 5 . In the case of run 14, the volume fraction profiles of each solid tended to develop to flat profiles (quite uniform) beyond $1.0 \mathrm{~m}$ height, but occurred faster than in run 19 and also, they were very dilute from this height in accordance with the axial profile in Fig. 9. These flat and very dilute profiles confirmed that the flow pattern in run 14 was in dilute transportation and could be a cause for the lowest $\mathrm{H}_{2}$ flux and the lowest $\mathrm{H}_{2}$ purity. Hence, from both runs, the concentration of each solid was the key hydrodynamic for performing SESRE in the CFBR riser.

As shown in Fig. 12, the time-averaged radial profiles of the volumetric catalyst-to-sorbent ratio at different heights in both runs are plotted for comparing with the ratio with which the solid entered ( $1.778 \mathrm{v} / \mathrm{v}$ in run 19 and $0.4085 \mathrm{v} / \mathrm{v}$ in run 14). The profile of the $0.1 \mathrm{~m}$ height in run 19 and the profiles of the 0.1$2.0 \mathrm{~m}$ height in run 14 near the left wall showed slightly higher ratio than the inlet ratio. This is because the solids entered from the channel on the right wall with normal direction to the wall, so more of the heavier catalyst could flow directly to the left wall than the sorbent, while more of the lighter sorbent would be lifted up at the right zone than the catalyst. However, the radial- 
averaged ratio of each height was nearly equal that with which the solids entered. Thus, the segregation between the catalyst and the sorbent in the radial direction did not severely affect SESRE, consistent with the axial profile of the volumetric catalyst-to-sorbent ratio discussed previously in Fig. 9, the segregation between the catalyst and the sorbent did not cause the incomplete performance of SESRE in this system.

Overall, the major cause of the incomplete operations of SESRE in the CFBR system with these ranges of parameters was the dilute region in the core of the riser, which led to an insufficient gas-solids contact before the gas left the riser. Even though the CFBR system with the best case still did not achieve the perfect SESRE performance, the $\mathrm{H}_{2}$ purity could be raised highly up to $91.30 \%$ on a dry basis by sorption enhancement. Compared to the packed-bed reactor, in which the gas and solids have sufficient contact time, SESRE could be performed perfectly with $\mathrm{H}_{2}$ purity $96.2 \%$ on a dry basis in the experiment of Olivas et $a .^{18}$ and $98.5 \%$ in the validating simulation, as shown in Table 3. Thus, the CFB riser with better modifications of design and/or operation might enable a better gas-solid contact for perfect SESRE performance. However, verifying experiments are suggested to confirm this system design.

\section{Conclusion}

In the present study, 2D transient models for gas-solid flows using a Euler-Euler approach accompanied with the KTGF theory and kinetic models of SRE on a Ni-based catalyst and carbonation on the dolomite sorbent were applied for simulating SESRE in a CFB riser. The pilot-scale riser design and operation were determined for the best performance of $\mathrm{H}_{2}$ production by studying the five most effective parameters involving the design parameters (the riser diameter, the gas velocity, and the solid flux) and the reaction parameters (the inlet temperature and the catalyst-to-sorbent ratio). The $2^{5}$ full factorial design method was utilized to investigate the effects of each parameter on the $\mathrm{H}_{2}$ flux and the $\mathrm{H}_{2}$ purity, and to predict the optimum case of both the $\mathrm{H}_{2}$ flux and the $\mathrm{H}_{2}$ purity. Many cases of the 32 runs indicated that SESRE could perform well in the system, even though neither of them achieved the extreme level as determined in theoretical equilibrium or in the packedbed rector. The $\mathrm{CaO}$ conversion was not over $28 \%$ of the circulating limitation in every case. Thus, SESRE could possibly be operated in the CFBR system.

According to the results of the ANOVAs, either the main effect or its interaction with each parameter occurred and was significant with the $\mathrm{H}_{2}$ flux or the $\mathrm{H}_{2}$ purity. In descending order, the catalyst-to-sorbent ratio, the solid flux, the riser diameter, the inlet temperature, and the gas velocity had highly significant effects on the $\mathrm{H}_{2}$ flux. Moreover, the solid flux, the riser diameter, the gas velocity, and the catalyst-to-sorbent ratio had highly significant effects on the $\mathrm{H}_{2}$ purity. Remarkably, the main effects of the riser diameter and the solid flux and their interactions were significant to both the $\mathrm{H}_{2}$ flux and the $\mathrm{H}_{2}$ purity. Therefore, the riser diameter and the solid flux, which are both design parameters, were the key parameters for $\mathrm{H}_{2}$ production performance in this system. Moreover, most of the main effects and interactions positively affected both the $\mathrm{H}_{2}$ flux and the $\mathrm{H}_{2}$ purity; whereas the inlet temperature had a negative effect on the $\mathrm{H}_{2}$ flux and the gas velocity was negative to the $\mathrm{H}_{2}$ purity.

From predictions using regression models, the best case of SESRE in this CFB riser was simulated with riser diameter of 0.2 $\mathrm{m}$, inlet temperature of $600{ }^{\circ} \mathrm{C}$, catalyst-to-sorbent ratio of 2.54 $\mathrm{kg} \mathrm{kg}{ }^{-1}$, solid flux of $200 \mathrm{~kg} \mathrm{~m}^{-2} \mathrm{~s}^{-1}$, and gas velocity of $3 \mathrm{~m} \mathrm{~s}^{-1}$ to possibly achieve the highest $\mathrm{H}_{2}$ purity of $91.30 \%$ on a dry basis with a maximum $\mathrm{H}_{2}$ flux of $0.147 \mathrm{~kg} \mathrm{~m}^{-2} \mathrm{~s}^{-1}$.

Considering the hydrodynamics inside the riser for the best case, first of all, the solid flow was a core-annular pattern of fast fluidization, in which the bed was denser in the lower zone, as might be called a high-dense circulation fluidized bed (HDCFB). Thus, the performance of SESRE reached breakthrough in this dense zone. Next, the good mixing of the catalyst and the sorbent all along both the axial and radial directions indicated that the segregation between the catalyst and the sorbent was not the cause of the incomplete performance. The bed in the core of the riser was very dilute almost along the entire axial direction, and this was the actual cause for the incompletion of SESRE in this system, even in the best case.

\section{Conflicts of interest}

There are no conflicts to declare.

\section{Nomenclature}

\begin{tabular}{|c|c|}
\hline$C_{\mathrm{D}}$ & Drag coefficient, $[-]$ \\
\hline$C_{\mathrm{fr}, \mathrm{ls}}$ & Friction coefficient between solid phases, $[-]$ \\
\hline $\mathrm{Cat} / \mathrm{Sb}$ & Catalyst-to-sorbent ratio, $\left[\mathrm{kg} \mathrm{kg}^{-1}\right]$ \\
\hline$d_{\mathrm{s}}$ & Particle diameter of the solid phase, $[\mathrm{m}]$ \\
\hline$e_{\mathrm{ss}} \equiv e_{\mathrm{ls}}$ & Restitution coefficient for solid-solid collisions, [-] \\
\hline$G_{\mathrm{S}}$ & Solid flux, $\left[\mathrm{kg} \mathrm{m}^{-2} \mathrm{~s}^{-1}\right]$ \\
\hline$\vec{g}$ & Gravity force, $\left[\mathrm{m} \mathrm{s}^{-2}\right]$ \\
\hline$g_{0,1 \mathrm{~s}}$ & $\begin{array}{l}\text { Radial distribution coefficient of mutual solid phases, } \\
{[-]}\end{array}$ \\
\hline$g_{0, \mathrm{ss}}$ & $\begin{array}{l}\text { Radial distribution coefficient of single solid phase, } \\
{[-]}\end{array}$ \\
\hline$H$ & Height of the riser, $[\mathrm{m}]$ \\
\hline$H_{\mathrm{g}}$ & Specific enthalpy of the gas phase, $\left[\mathrm{m}^{2} \mathrm{~s}^{-2}, \mathrm{~J} \mathrm{~kg}^{-1}\right]$ \\
\hline$h_{\mathrm{sg}} \equiv$ & Gas-solid interphase heat exchange coefficient, $\left[\mathrm{m}^{2}\right.$ \\
\hline$h_{\mathrm{gs}}$ & $\left.\mathrm{s}^{-2}, \mathrm{~J} \mathrm{~kg}^{-1}\right]$ \\
\hline $\bar{I}$ & Unit tensor, $[-]$ \\
\hline$i_{\mathrm{d}_{\mathrm{q}}}$ & Diameter of the riser, $[\mathrm{m}]$ \\
\hline$\vec{J}_{\mathrm{k}}^{\mathrm{q}}$ & Mass flux of species $\mathrm{k}$ into phase $\mathrm{q},\left[\mathrm{kg} \mathrm{m}^{-2} \mathrm{~s}^{-1}\right]$ \\
\hline$K_{\mathrm{i}}$ & Equilibrium constants of reaction $\mathrm{i}$ \\
\hline$K_{\mathrm{k}}$ & Adsorption equilibrium constants of species $\mathrm{k}$ \\
\hline$K_{\mathrm{ls}} \equiv$ & Solid-solid interphase momentum exchange \\
\hline$K_{\mathrm{sl}}$ & coefficient, $\left[\mathrm{kg} \mathrm{m}^{-3} \mathrm{~s}^{-1}\right]$ \\
\hline$K_{\mathrm{sg}} \equiv$ & Gas-solid interphase momentum exchange \\
\hline$K_{\mathrm{gs}}$ & coefficient, $\left[\mathrm{kg} \mathrm{m}^{-3} \mathrm{~s}^{-1}\right]$ \\
\hline$k_{\text {carb }}$ & Rate constants of carbonation \\
\hline$k_{\mathrm{g}}$ & Thermal conductivity of the gas phase, $\left[\mathrm{W} \mathrm{m}{ }^{-1} \mathrm{~K}^{-1}\right]$ \\
\hline$k_{\mathrm{i}}$ & Rate constants of reaction $\mathrm{i}$ \\
\hline$k_{\Theta_{\mathrm{s}}}$ & Diffusion coefficient, $\left[\mathrm{m}^{2} \mathrm{~s}^{-1}\right]$ \\
\hline
\end{tabular}


$\dot{m}_{\mathrm{pq}} \quad$ Mass transfer from phase $\mathrm{p}$ to phase $\mathrm{q},\left[\mathrm{kg} \mathrm{m}^{-3} \mathrm{~s}^{-1}\right]$

$\mathrm{Nu}_{\mathrm{s}} \quad$ Nusselt number of the solid phase, [-]

$n \quad$ Degree of partial pressure, $[-]$

Pr Prandtl number of the gas phase, [-]

$p \quad$ Static pressure, $[\mathrm{Pa}]$

$p_{\mathrm{CO}_{2}} \quad$ Partial pressure of $\mathrm{CO}_{2},[\mathrm{~Pa}]$

$p_{\mathrm{CO}_{2}, \text { eq }} \quad$ Equilibrium pressures of $\mathrm{CO}_{2},[\mathrm{~Pa}]$

$p_{\mathrm{g}} \quad$ Static pressure of the gas phase, $[\mathrm{Pa}]$

$p_{\mathrm{k}} \quad$ Partial pressures of species $\mathrm{k},[\mathrm{Pa}]$

$p_{\mathrm{s}} \quad$ Solid pressure, $[\mathrm{Pa}]$

$Q_{\text {sg }} \quad$ Intensity of heat exchange between the solid phase and gas phase, $\left[\mathrm{W} \mathrm{m}^{-3}\right]$

$\vec{q}_{\mathrm{g}} \quad$ Heat flux of the gas phase, $\left[\mathrm{W} \mathrm{m}^{-2}\right]$

$R_{\mathrm{k}}^{\mathrm{q}} \quad$ Net rate of species k produced by homogeneous reactions inside phase $\mathrm{q},\left[\mathrm{kg} \mathrm{m} \mathrm{m}^{-3} \mathrm{~s}^{-1}\right]$

$\mathrm{Re}_{\mathrm{s}} \quad$ Particle Reynolds number of the solid phase, [-]

$r_{\text {carb }} \quad$ Rate of carbonation, $\left[\mathrm{kmol} \mathrm{kg}_{\text {sorb }}{ }^{-1} \mathrm{~s}^{-1}\right]$

$r_{\mathrm{i}} \quad$ Rates of reaction i, [ $\mathrm{kmol} \mathrm{kg}_{\mathrm{cat}}^{-1} \mathrm{~s}^{-1}$ ]

$S_{\mathrm{h}, \mathrm{g}} \quad$ Heat source of the gas phase, $\left[\mathrm{W} \mathrm{m}^{-3}\right]$

$S_{\mathrm{k}}^{\mathrm{q}} \quad$ Rate of creation of species $\mathrm{k}$ by addition from the dispersed phase and other sources in phase $\mathrm{q},[\mathrm{kg}$ $\mathrm{m}^{-3} \mathrm{~s}^{-1}$ ]

$S_{\mathrm{m}, \mathrm{q}} \quad$ Mass source of phase q, $\left[\mathrm{kg} \mathrm{m}^{-3} \mathrm{~s}^{-1}\right]$

$S_{0} \quad$ Initial specific surface area of $\mathrm{CaO},\left[\mathrm{m}^{2} \mathrm{~kg}_{\text {sorb }}{ }^{-1}\right]$

$\mathrm{S} / \mathrm{E} \quad$ Steam/ethanol molar ratio, $\left[\mathrm{mol} \mathrm{mol}^{-1}\right]$

$T_{\text {in }} \quad$ Temperature of the inlets, $\left[{ }^{\circ} \mathrm{C}\right]$

$U \quad$ Gas inlet velocity, $\left[\mathrm{m} \mathrm{s}^{-1}\right]$

$\vec{\nu}_{1 \mathrm{~s}} \quad$ Interphase velocity from phase 1 (solid or gas) to the solid phase, $\left[\mathrm{m} \mathrm{s}^{-1}\right]$

$\vec{\nu}_{\mathrm{q}} \quad$ Velocity of phase $\mathrm{q},\left[\mathrm{m} \mathrm{s}^{-1}\right]$

$\vec{\nu}_{\mathrm{sg}} \quad$ Interphase velocity from the solid phase to gas phase, $\left[\mathrm{m} \mathrm{s}^{-1}\right]$

$X_{\mathrm{CaO}} \quad$ Conversion of $\mathrm{CaO},[-]$

$Y_{\mathrm{k}}^{\mathrm{q}} \quad$ Mass fraction of species $\mathrm{k}$ in phase $\mathrm{q},[-]$

$\gamma_{\Theta_{\mathrm{s}}} \quad$ Collisional dissipation of energy, $\left[\mathrm{W} \mathrm{m}^{-3}\right]$

$\varepsilon_{\mathrm{q}} \quad$ Volume fraction of phase $\mathrm{q},[-]$

$\varepsilon_{\mathrm{S}, \max } \quad$ Maximum packing of the solid phase, [-]

$\Theta_{\mathrm{s}} \quad$ Granular temperature, $\left[\mathrm{m}^{2} \mathrm{~s}^{-2}, \mathrm{~J} \mathrm{~kg}^{-1}\right]$

$\lambda_{\mathrm{q}} \quad$ Bulk viscosity of phase $\mathrm{q},[\mathrm{Pa} \mathrm{s}]$

$\lambda_{\mathrm{s}} \quad$ Solid bulk viscosity, [Pa s]

$\mu_{\mathrm{q}} \quad$ Shear viscosity of phase q, [Pa s]

$\mu_{\mathrm{s}} \quad$ Solid shear viscosity, [Pa s]

$\mu_{\mathrm{s}, \mathrm{col}} \quad$ Collisional viscosity of the solid phase, [Pa s]

$\mu_{\mathrm{s}, \mathrm{fr}} \quad$ Friction viscosity of the solid phase, [Pa s]

$\mu_{\mathrm{s}, \mathrm{kin}} \quad$ Kinetic viscosity of the solid phase, [Pa s]

$\rho_{\mathrm{q}} \quad$ Physical density of phase $\mathrm{q},\left[\mathrm{kg} \mathrm{m} \mathrm{m}^{-3}\right]$

$\overline{\tau_{\mathrm{q}}} \quad$ Stress tensor of phase $\mathrm{q},[\mathrm{Pa}]$

$\tau_{\mathrm{s}} \quad$ Particulate relaxation time in the solid phase, [s]

$\phi_{\mathrm{ls}} \quad$ Kinetic energy exchange between phase l (solid or gas) and the solid phase, $\left[\mathrm{W} \mathrm{m}^{-3}\right]$

\section{Acknowledgements}

The authors would like to acknowledge the support from the Ratchadapisek Sompoch Endowment Fund (2016), Chulalongkorn University (CU-59-003-IC). B. Chalermsinsuwan also would like to thank the support from the Thailand Research
Fund (RSA5980052). S. Assabumrungrat and S. Putivisutisak also acknowledge the NSTDA Chair Professor Grant (No. 5) funded by the Crown Property Bureau of Thailand and National Science and Technology Development Agency.

\section{References}

1 F. Joensen and J. R. Rostrup-Nielsen, Conversion of hydrocarbons and alcohols for fuel cells, J. Power Sources, 2002, 105, 195-201.

2 J. L. Contreras, J. Salmones, J. A. Colín-Luna, L. Nuño, B. Quintana, I. Córdova, B. Zeifert, C. Tapia and G. A. Fuentes, Catalysts for $\mathrm{H}_{2}$ production using the ethanol steam reforming (a review), Int. J. Hydrogen Energy, 2014, 39, 18835-18853.

3 G. Wu, C. Zhang, S. Li, Z. Huang, S. Yan, S. Wang, X. Ma and J. Gong, Sorption enhanced steam reforming of ethanol on $\mathrm{Ni}-\mathrm{CaO}-\mathrm{Al}_{2} \mathrm{O}_{3}$ multifunctional catalysts derived from hydrotalcite-like compounds, Energy Environ. Sci., 2012, 5, 8942-8949.

4 M. A. Ebiad, D. R. Abd El-Hafiz, R. A. Elsalamony and L. S. Mohamed, Ni supported high surface area $\mathrm{CeO}_{2}-\mathrm{ZrO}_{2}$ catalysts for hydrogen production from ethanol steam reforming, RSC Adv., 2012, 2, 8145-8156.

5 A. Rautio, P. K. Seelam, P. Maki-Arvela, O. Pitkanen, M. Huuhtanen, R. L. Keiski and K. Kordasa, Carbon supported catalysts in low temperature steam reforming of ethanol: study of catalyst performance, RSC Adv., 2015, 5, 49487-49492.

6 F. Liu, Y. Qu, Y. Yue, G. Liu and Y. Liu, Nano bimetallic alloy of Ni-Co obtained from $\mathrm{LaCo}_{x} \mathrm{Ni}_{1-x} \mathrm{O}_{3}$ and its catalytic performance for steam reforming of ethanol, RSC $A d v$, 2015, 5, 16837-16846.

7 Z. Zhao, P. Ren and W. Li, Supported Ni catalyst on a natural halloysite derived silica-alumina composite oxide with unexpected coke-resistant stability for steam- $\mathrm{CO}_{2}$ dual reforming of methane, RSC Adv., 2016, 6, 49487-49496.

8 P. Vaidya and A. E. Rodrigues, Insight into steam reforming of ethanol to produce hydrogen for fuel cells: a review, Chem. Eng. J., 2006, 117, 39-49.

9 Y. J. Wu, P. Li, J. G. Yu, A. F. Cunha and A. E. Rodrigues, Sorption-enhanced steam reforming of ethanol on NiMgAl multifunctional materials: Experimental and numerical investigation, Chem. Eng. J., 2013, 231, 36-48.

10 Y. J. Wu, P. Li, J. G. Yu, A. F. Cunha and A. E. Rodrigues, Sorption-enhanced steam reforming of ethanol for continuous high-purity hydrogen production: 2D adsorptive reactor dynamics and process design, Chem. Eng. Sci., 2014, 118, 83-93.

11 Y. J. Wu, P. Li, J. G. Yu, A. F. Cunha and A. E. Rodrigues, High-purity hydrogen production by sorption-enhanced steam reforming of ethanol: a cyclic operation simulation study, Ind. Eng. Chem. Res., 2014, 53, 8515-8527.

12 Y. J. Wu, J. C. Santos, P. Li, J. G. Yu, A. F. Cunha and A. E. Rodrigues, Simplified kinetic model for steam reforming of ethanol on a $\mathrm{Ni} / \mathrm{Al}_{2} \mathrm{O}_{3}$ catalyst, Can. J. Chem. Eng., 2014, 92, 116-130. 
13 A. F. Cunha, Y. J. Wu, F. A. Diaz Alvarado, J. C. Santos, P. D. Vaidya and A. E. Rodrigues, Steam reforming of ethanol on a $\mathrm{Ni} / \mathrm{Al}_{2} \mathrm{O}_{3}$ catalyst coupled with a hydrotalcitelike sorbent in a multilayer pattern for $\mathrm{CO}_{2}$ uptake, Can. J. Chem. Eng., 2012, 90, 1514-1526.

14 A. Haryanto, S. Fernando, N. Murali and S. Adhikari, Current status of hydrogen production techniques by steam reforming of ethanol: A review, Energy Fuels, 2005, 19, 2098-2106.

15 M. De-Souza, G. M. Zanin and F. F. Moraes, Parametric study of hydrogen production from ethanol steam reforming in a membrane microreactor, Braz. J. Chem. Eng., 2013, 30, 355-367.

16 J. Sun, X. Qiu, F. Wu and W. Zhu, $\mathrm{H}_{2}$ from steam reforming of ethanol at low temperature over $\mathrm{Ni}-\mathrm{Y}_{2} \mathrm{O}_{3}, \mathrm{Ni}-\mathrm{La}_{2} \mathrm{O}_{3}$ and $\mathrm{Ni}-\mathrm{Al}_{2} \mathrm{O}_{3}$ catalysts for fuel-cell application, Int. J. Hydrogen Energy, 2005, 30, 437-445.

17 V. Mas, M. L. Bergamini, G. Baronetti, N. Amadeo and M. Laborde, A kinetic study of ethanol steam reforming using a nickel based catalyst, Top. Catal., 2008, 51, 39-48.

18 D. Y. Aceves Olivas, M. R. Baray Guerrero, M. A. Escobedo Bretado, M. Marques da Silva Paula, J. Salinas Gutiérrez, V. Guzmán Velderrain, A. López Ortiz and V. CollinsMartínez, Enhanced ethanol steam reforming by $\mathrm{CO}_{2}$ absorption using $\mathrm{CaO}, \mathrm{CaO}^{*} \mathrm{MgO}$ or $\mathrm{Na}_{2} \mathrm{ZrO}_{3}$, Int. J. Hydrogen Energy, 2014, 39, 16595-16607.

19 L. Barelli, G. Bidini, F. Gallorini and S. Servili, Hydrogen production through sorption-enhanced steam methane reforming and membrane technology: a review, Energy, 2008, 33, 554-570.

20 S. D. Kenarsari, D. Yang, G. Jiang, S. Zhang, J. Wang, A. G. Russell, Q. Wei and M. Fan, Review of recent advances in carbon dioxide separation and capture, $R S C$ Adv., 2013, 3, 22739-22773.

21 D. P. Harrison, Sorption-enhanced hydrogen production: a review, Ind. Eng. Chem. Res., 2008, 47, 6486-6501.

22 A. Cotton, K. Patchigolla and J. E. Oakey, Overview of, and experimental methodology for sorption enhanced hydrogen production, Energy Procedia, 2013, 37, 2232-2244.

23 A. E. Rodrigues, Y. J. Wu, R. Faria and L. M. Madeira, Sorption Enhanced Reaction Processes, World Scientific Publishing, USA, 2017.

24 R. Singh, M. K. Ram Reddy, S. Wilson, K. Joshi, J. C. Diniz da Costa and P. Webley, High temperature materials for $\mathrm{CO}_{2}$ capture, Energy Procedia, 2009, 1, 623-630.

25 M. Sayyah, B. R. Ito, M. Rostam-Abadi, Y. Lu and K. S. Suslick, CaO-based sorbents for $\mathrm{CO}_{2}$ capture prepared by ultrasonic spray pyrolysis, RSC Adv., 2013, 3, 1987219875.

26 A. Islam, S. H. Teo, E. S. Chan and Y. H. Taufiq-Yap, Enhancing the sorption performance of surfactant-assisted CaO nanoparticles, RSC Adv., 2014, 4, 65127-65136.

$27 \mathrm{H}$. Ping and S. Wu, Preparation of cage-like nano- $\mathrm{CaCO}_{3}$ hollow spheres for enhanced $\mathrm{CO}_{2}$ sorption, $R S C A d v ., 2015$, 5, 65052-65057.
28 J. Comas, M. Laborde and N. Amadeo, Thermodynamic analysis of hydrogen production from ethanol using $\mathrm{CaO}$ as a $\mathrm{CO}_{2}$ sorbent, J. Power Sources, 2004, 138, 61-67.

29 A. L. da Silva and I. L. Muller, Hydrogen production by sorption enhanced steam reforming of oxygenated hydrocarbons (ethanol, glycerol, $n$-butanol and methanol): thermodynamic modelling, Int. J. Hydrogen Energy, 2011, 36, 2057-2075.

30 Z. Chao, Y. Wang, J. P. Jakobsen, M. Fernandino and H. A. Jakobsen, Numerical investigation of the sorption enhanced steam methane reforming in a fluidized bed reactor, Energy Procedia, 2012, 26, 15-21.

31 Y. Wang, Z. Chao and H. A. Jakobsen, 3D Simulation of bubbling fluidized bed reactors for sorption enhanced steam methane reforming processes, J. Nat. Gas Sci. Eng., 2010, 2, 105-113.

32 K. Johnsen, J. R. Grace, S. S. E. H. Elnashaie, L. Kolbeinsen and D. Eriksen, Modeling of sorption-enhanced steam reforming in a dual fluidized bubbling bed reactor, Ind. Eng. Chem. Res., 2006, 45, 4133-4144.

33 K. Johnsen, H. J. Ryu, J. R. Grace and C. J. Lim, Sorptionenhanced steam reforming of methane in a fluidized bed reactor with dolomite as $\mathrm{CO}_{2}$-acceptor, Chem. Eng. Sci., 2006, 61, 1195-1202.

34 A. G. Gayubo, J. Vicente, J. Erena, C. Montero, M. Olazar and J. Bilbao, Comparison of $\mathrm{Ni}$ and Co catalysts for ethanol steam reforming in a fluidized bed reactor, Catal. Lett., 2014, 144, 1134-1143.

35 J. Vicente, C. Montero, J. Erena, M. J. Azkoiti, J. Bilbao and A. G. Gayubo, Coke deactivation of $\mathrm{Ni}$ and Co catalysts in ethanol steam reforming at mild temperatures in a fluidized bed reactor, Int. J. Hydrogen Energy, 2014, 39, 21586-21596.

36 D. Kunii and O. Levenspiel, Fluidization engineering, Butterworth-Heinemann, USA, 1991.

37 M. B. M. Mousa, S. E. K. Fateen and E. A. Ibrahim, Hydrodynamics of a novel design circulating fluidized bed steam reformer operating in the dense suspension upflow regime, ISRN Chem. Eng., 2014, 2014, 1-13.

38 Y. Prajongkan, Three-dimensional simulation of hydrodynamics in riser of circulating fluidized bed reactor, Thesis of the degree of Master of Science, Chulalongkorn University, 2011.

39 B. Arstad, J. Prostak and R. Blom, Continuous hydrogen production by sorption enhanced steam methane reforming (SE-SMR) in a circulating fluidized bed reactor: Sorbent to catalyst ratio dependencies, Chem. Eng. J., 2012, 189-190, 413-421.

40 Y. Wang, Z. Chao, D. Chen and H. A. Jakobsen, SE-SMR process performance in CFB reactors: Simulation of the $\mathrm{CO}_{2}$ adsorption/desorption processes with $\mathrm{CaO}$ based sorbents, Int. J. Greenhouse Gas Control, 2011, 5, 489-497.

41 N. Rodríguez, M. Alonso and J. C. Abanades, Experimental investigation of a circulating fluidized-bed reactor to capture $\mathrm{CO}_{2}$ with CaO, AIChE J., 2011, 57, 1356-1366. 
42 J. Wang, Y. Wang and H. A. Jakobsen, The modeling of circulating fluidized bed reactors for SE-SMR process and sorbent regeneration, Chem. Eng. Sci., 2014, 108, 57-65.

43 A. Di Carlo, E. Bocci, F. Zuccari and A. Dell'Era, Numerical investigation of sorption enhanced steam methane reforming process using computational fluid dynamics Eulerian-Eulerian code, Ind. Eng. Chem. Res., 2010, 49, 1561-1576.

44 T. Samruamphianskun, P. Piumsomboon and B. Chalermsinsuwan, Effect of ring baffle configurations in a circulating fluidized bed riser using CFD simulation and experimental design analysis, Chem. Eng. J., 2012, 210, 237-251.

45 B. Chalermsinsuwan, T. Samruamphianskun and P. Piumsomboon, Effect of operating parameters inside circulating fluidized bed reactor riser with ring baffles using CFD simulation and experimental design analysis, Chem. Eng. Res. Des., 2014, 92, 2479-2492.

46 V. V. Ranade, Computational flow modeling for chemical reactor engineering, Academic Press, UK, 2002.

47 G. H. Yeoh and J. Tu, Computational techniques for multiphase flows, Elsevier Ltd, UK, 2010.

48 D. Gidaspow, Multiphase Flow and Fluidization: Continuum and Kinetic Theory Description, Academic Press, UK, 1994.

49 R. A. Sánchez, Z. Chao, J. Solsvik and H. A. Jakobsen, One dimensional two-fluid model simulations of the SE-SMR process operated in a circulating fluidized bed reactor, Procedia Eng., 2012, 42, 1282-1291.

50 R. A. Sánchez, J. Solsvik and H. A. Jakobsen, Modeling and simulation of cold flow fluidized bed reactors, Energy Procedia, 2012, 26, 22-30.

51 R. A. Sánchez, Z. Chao, J. Solsvik and H. A. Jakobsen, An investigation of the heat integration between the two riser units constituting a circulating fluidized bed reactor for the SE-SMR process, Energy Procedia, 2013, 37, 1218-1227.

52 J. Solsvik, Z. Chao and H. A. Jakobsen, A one-dimensional two-fluid gas-solid model applied to fluidized bed reactors: The SMR and SE-SMR processes, Procedia Eng., 2012, 42, 283-294.

53 J. Solsvik, Z. Chao, R. A. Sánchez and H. A. Jakobsen, Numerical investigation of steam methane reforming with $\mathrm{CO}_{2}$-capture in bubbling fluidized bed reactors, Fuel Process. Technol., 2014, 125, 290-300.

54 Y. Wang, Z. Chao and H. A. Jakobsen, CFD modelling of $\mathrm{CO}_{2}$ capture in the SE-SMR process in the fluidized bed reactors, Chem. Eng. Trans., 2010, 21, 601-606.

55 S. Song, Z. Hao, L. Dong, J. Li and Y. Fang, A bubble-based EMMS model for pressurized fluidization and its validation with data from a jetting fluidized bed, RSC Adv., 2016, 6, 111041-111051.

56 Z. Chao, Y. Wang, J. P. Jakobsen, M. Fernandino and H. A. Jakobsen, Derivation and validation of a binary multi-fluid Eulerian model for fluidized beds, Chem. Eng. Sci., 2011, 66, 3605-3616.

57 H. Lindborg, M. Lysberg and H. A. Jakobsen, Practical validation of the two-fluid model applied to dense gassolid flows in fluidized beds, Chem. Eng. Sci., 2007, 62, 5854-5869.

58 M. J. Hodapp, J. J. Ramirez-Behainne, M. Mori and L. Goldstein Jr, Numerical studies of the gas-solid hydrodynamics at high temperature in the riser of a bench-scale circulating fluidized bed, Int. J. Chem. Eng., 2012, 2012, 786982.

59 R. A. Sánchez and H. A. Jakobsen, Simulation of sorption enhanced steam methane reforming and chemical looping reforming in a circulating fluidized bed reactor, Ninth International Conference on CFD in the Minerals and Process Industries, CSIRO, Melbourne, Australia, 2012, pp. 1-6.

60 J. Solsvik, R. A. Sánchez, Z. Chao and H. A. Jakobsen, Simulations of steam methane reforming/sorptionenhanced steam methane reforming bubbling fluidized bed reactors by a dynamic one-dimensional two-fluid model: Implementation issues and model validation, Ind. Eng. Chem. Res., 2013, 52, 4202-4220.

61 Y. Chen, Y. Zhao, C. Zheng and J. Zhang, Numerical study of hydrogen production via sorption-enhanced steam methane reforming in a fluidized bed reactor at relatively low temperature, Chem. Eng. Sci., 2013, 92, 67-80.

$62 \mathrm{~J}$. $\mathrm{Xu}$ and G. F. Froment, Methane steam reforming, methanation and water-gas shift: I.Intrinsic kinetics, AIChE J., 1989, 35, 88-96.

63 G. Xiu, P. Li and A. E. Rodrigues, Sorption-enhanced reaction process with reactive regeneration, Chem. Eng. Sci., 2002, 57, 3893-3908.

64 P. Sun, J. R. Grace, C. J. Lim and E. J. Anthony, Determination of intrinsic rate constants of the $\mathrm{CaO}-\mathrm{CO}_{2}$ reaction, Chem. Eng. Sci., 2008, 63, 47-56.

65 J. C. Abanades, E. J. Anthony, D. Y. Lu, C. Salvador and D. Alvarez, Capture of $\mathrm{CO}_{2}$ from combustion gases in a fluidized bed of CaO, AIChE J., 2004, 50, 1614-1622.

66 J. S. Lin, M. M. Chen and B. T. Chao, A novel radioactive particle tracking facility for measurement of solids motion in gas fluidized beds, AIChE J., 1985, 31, 465-473.

67 D. C. Montgomery, Design and Analysis of Experiments, John Wiley and Sons, USA, 2012.

68 D. Kunii and O. Levenspiel, Circulating fluidized-bed reactors, Chem. Eng. Sci., 1997, 52, 2471-2482.

69 S. Mahmoudi, C. W. Chan, A. Brems, J. Seville and J. Baeyens, Solids flow diagram of a CFB riser using Geldart B-type powders, Particuology, 2012, 10, 51-61.

70 J. Zhu, Circulating turbulent fluidization-A new fluidization regime or just a transitional phenomenon, Particuology, 2010, 8, 640-644. 